\title{
Validation of a lumped-mass mooring line model with DeepCwind semisubmersible model test data
}

\author{
Matthew Hall*, Andrew Goupee \\ Department of Mechanical Engineering, University of Maine, Maine, USA
}

\begin{abstract}
This paper introduces a lumped-mass mooring line model and validates it against scale-model floating offshore wind turbine test data. The mooring model incorporates axial elasticity, hydrodynamic loading via Morison's equation, and bottom contact. It neglects bending and torsional stiffnesses for the sake of computation speed. A coupling with the floating wind turbine simulator FAST allows simulation of complete floating wind turbine systems including mooring dynamics. The DeepCwind semisubmersible floating wind turbine design was simulated and the results compared with data from previously-published 1:50-scale experiments. Uncoupled simulations in which the fairlead motions are prescribed according to the test data show very good agreement in fairlead tensions; predicted fatigue and extreme loads match the test data to within $10 \%$ and snap load conditions are predicted consistently. When the mooring model is coupled with FAST to simulate the entire floating wind turbine system, the fairlead tensions and the platform heave response are underpredicted relative to the test data, suggesting a limitation of the
\end{abstract}

*Correspondence: matthew.hall1@maine.edu, 1-207-299-2570, 5711 Boardman Hall, Room 219 Orono, ME 04469 USA 
platform hydrodynamic model. In all cases, using a quasi-static mooring model significantly underpredicts the mooring loads, especially for fatigue. In general, the results suggest that the lumped-mass mooring model is suitable for predicting mooring line loads of the DeepCwind semisubmersible. Keywords: floating, wind turbine, mooring model, lumped mass, fairlead tension, MoorDyn

\section{Introduction}

In floating offshore structures, mooring modeling plays an important role in predicting the global response of the platform and predicting the loads on the mooring lines. Since mooring systems are sized based on the extreme and fatigue loadings expected over their lifetime, accurate prediction of these loads is of obvious interest. This interest is even greater for offshore renewable energy systems, since the energy conversion processes involved often make for large dynamic loads on the mooring system and the slim profit margins necessitate low safety factors in the design.

Quasi-static models, a popular and simple approach to mooring modeling, solve for the continuous mooring line profile and tension using a set of analytical equations based on the assumption that the line is in static equilibrium. This type of model has been popular for use in floating wind turbine simulations because it is computationally efficient, easy to work with, and available in open-source implementations (eg. Masciola et al., 2013a). The main disadvantage is that quasi-static models neglect hydrodynamic and inertial forces on the line, which can affect the platform response and are especially important for predicting the mooring loads. 
To accurately predict the loads on the mooring lines themselves, which is critical to ensuring a mooring system's safe design, a model that incorporates mooring line dynamics is usually required. A variety of dynamic mooring line models exist, many of which use a lumped-mass approach to discretize the cable behavior. Walton and Polachek (1959) lay the groundwork for discretized mooring line modeling with a two-dimensional finite-difference ${ }^{1}$ model that assumes rigid cable segments connected by joints without bending stiffness. Hydrodynamic drag and added mass forces are applied uniformly over each segment. The model provided convincing though unvalidated results showing that dynamics matter to the mooring loads. Khan and Ansari (1986) developed a lumped-mass approach in three dimensions. As in the previous case, the cable segments are assumed rigid and massless and subject to hydrodynamic forces, while the masses are concentrated at the node points. The model was successfully demonstrated while accounting for seabed contact and the presence of a clump weight on the cable. Huang (1994) developed a three-dimensional finite-difference model that incorporated axial elasticity of the cable, and demonstrated its capability by simulating a subsea unit being towed by a maneuvering vessel. More recently, Palm et al. (2013) developed a lumped-mass model using a discontinuous Galerkin method with the aim of better modeling snap loadings than the conventional discretization approaches. The model was verified against exact solutions and validated

\footnotetext{
${ }^{1}$ Finite-difference models discretize the governing equations in both space and time, making the time-stepping approach inherent to the formulation. Lumped-mass models, on the other hand, only discretize the governing equations in space, leaving continuous time derivatives; an external integration routine is then used to time-step the model.
} 
against laboratory experiments. Some lumped-mass models also incorporate discrete handling of bending stiffness at the node points.

The lumped-mass approach has also been extended to incorporate bending and torsional elasticity of the cable segments themselves, using the finiteelement analysis (FEA) approach (eg. Garrett, 1982; Malahy, 1985; McNamara et al., 1988). Buckham (2003) developed an improved FEA model that approximates the cable profile using a cubic spline fit through the node points, giving the model sufficient fidelity to predict the dynamics of lowtension cables undergoing intricate deformations. These high fidelity features make FEA-based models good at accurately predicting mooring line behavior over a wide range of conditions. However, this comes at a computational cost; these mooring line models are slower to run and therefore less practical for some design applications such as modeling inside of an optimization process.

For simulating floating offshore wind turbines, a number of recent studies have shown that the use of dynamic mooring line models is in many cases necessary for accurately predicting loads. Prediction of mooring loads is critical for designing a mooring system to withstand extreme and fatigue loads over its service life, which is in turn crucial to a floating offshore wind system's safety. Kallesoe and Hansen (2011) compared coupled simulation results of a spar-buoy floating wind turbine with two different mooring models. They found that a dynamic FEA-based mooring model predicted lower tower loads but similar blade loads compared to a quasi-static lookup-table model in normal operating conditions. Mooring tensions are not mentioned. Matha et al. (2011) made a similar comparison using the OC3-Hywind design 
and a multi-body mooring line model, but with more focus on the platform and mooring response. They observed that the dynamic model predicted reduced platform motions and much larger mooring line fatigue loads than a quasi-static model. Masciola et al. (2013b) compared the response of the OC4-DeepCwind semisubmersible design in coupled simulations using FAST and the lumped-mass mooring model OrcaFlex, as well as the default quasistatic mooring model, against 1:50-scale test data. They found that platform motions were influenced by mooring dynamics only in extreme sea states but that mooring dynamics are important to prediction of mooring line tensions in all load cases.

Hall et al. (2014) compared quasi-static and FEA mooring line models across three designs representing the three stability classes using a variety of load cases. The conclusions from this broader study are consistent with the previous studies: mooring dynamics have an influence on platform motions only when those motions are large, and mooring dynamics are always important to the prediction of mooring line loads. This has important implications for determining when a dynamic mooring line model is necessary in a coupled analysis. For platforms with small responses in mild environmental conditions, an aero-hydro-elastic analysis with a quasi-static mooring model is suitable, provided a separate high-fidelity mooring analysis using the platform motions from the coupled analysis is conducted to determine the mooring loads. For platforms that have large responses or any platforms in severe environmental conditions, the dynamic mooring line model should be included in the coupled analysis.

A number of dynamic mooring line models beyond those used in the 
abovementioned comparison studies have also been applied to floating wind turbine simulation, including Azcona et al. (2011), Bae et al. (2011), and Koo et al. (2014). Most relevant to the current work, Koo et al. used a coupling of FAST and MLTSIM, featuring second-order wave loads and FEAbased mooring modeling, to study the coupled response of the DeepCwind semisubmersible and compare with 1:50-scale test data. Analyzing in the frequency domain, they found good agreement in platform and mooring tension responses, with the exception of some differences in heave; the simulation underpredicted the heave response at wave periods where Froude-Krylov and diffraction forces cancel, presumable because the platform hydrodynamics model did not adequately account for viscous wave forces.

One reason that the use of dynamic mooring models is a recent development for floating wind turbine analysis is that, unlike quasi-static models, implementations of dynamic mooring models have in the past only been available commercially; this closed-source nature has meant they are not always easily integrable into coupled floating wind turbine simulations. A computationally-efficient dynamic mooring model implementation that is open source and designed to link with existing floating offshore wind turbine simulation tools would make dynamic mooring modeling more accessible to the floating wind turbine research community.

In previous work with a FEA-based mooring model (Hall et al., 2014), a sensitivity study indicated that bending and torsional elasticity were of negligible importance to the mooring line tension responses for the barge, spar, and TLP platforms that were considered, regardless of load case. The results were the same whether the model used the significant bending stiffness 
of a wire rope or the non-existent bending stiffness of a chain (none of the designs used the pipe-style moorings found in some TLPs). This suggests that if a dynamic mooring line model were to be implemented without accounting for bending and torsional elasticity, it could produce adequate results for these types of designs at less computational cost than typical FEA-based mooring models, at least in terms of tension loads. Such a model would have application to offshore renewable energy devices and provide a more computationally efficient means of accounting for mooring line dynamics in the design process.

This premise motivated the creation of the mooring model described in this paper: a simple lumped-mass mooring line model that captures the dynamic line characteristics necessary for predicting tensions while avoiding the higher-fidelity features that would cause unnecessary additions to the computation time. This model foregoes the rotational degrees of freedom associated with a full FEA-based model in favor of using only translational degrees of freedom and considering elasticity in the axial direction only. We describe the details of the model in Section 2. We evaluated the model by applying it to simulation of the DeepCwind semisubmersible floating wind turbine design and comparing the results with 1:50-scale test data of the same design. Section 3 describes the design and its implementation in a simulation tool consisting of the new lumped-mass mooring model and FAST, a floating wind turbine simulator developed by the National Renewable Energy Laboratory (NREL). Section 4 presents results validating the mooring line model with the test data in an uncoupled analysis of the mooring system alone, in which the fairlead positions are driven by the test data. Section 5 presents results 
from simulations of the entire floating wind turbine system in comparison with the test data. Section 6 summarizes the conclusions drawn from the study.

\section{Lumped-Mass Mooring Line Model}

The mooring line model we present in this paper uses a lumped-mass approach to discretize the cable dynamics over the length of the mooring line. In this approach, illustrated in Figure 1, the cable is broken up into $N$ evenly-sized line segments connecting $N+1$ node points. The indexing starts at the anchor, with the anchor node given a value of 0 and the cable segment between nodes 0 and 1 given an index of $1 / 2$.

The right-handed inertial reference frame is defined with the $z$ axis being measured positive up from the water plane. The location of each node point $i$ is defined by the vector $\mathbf{r}_{i}$ which contains the $x, y$, and $z$ coordinates of the node position. Each segment $i+\frac{1}{2}$ of a cable has identical properties of unstretched length $(l)$, volume-equivalent diameter $(d)$, density $(\rho)$, Young's modulus $(E)$, and internal damping coefficient $\left(C_{\text {int }}\right)$. The model allows cables with different sets of properties and supports features such as point masses and line interconnections; however, these are outside the scope of this study.

The cable model combines internal axial stiffness and damping forces with weight and buoyancy forces, hydrodynamic forces from Morison's equation, and forces from contact with the seabed. These forces are illustrated as vectors in Figure 2. The internal stiffness and damping forces in cable

segment $i+\frac{1}{2}$ are represented by $\mathbf{T}_{i+\frac{1}{2}}$ and $\mathbf{C}_{i+\frac{1}{2}}$, respectively. The cable 
weight lumped at each node $i$ is represented by $\mathbf{W}_{i}$.

The model calculates the hydrodynamic loads directly at the node points rather than the more common approach of calculating the hydrodynamic forces at the segment midpoints and then distributing them to the node points (eg. Walton and Polachek, 1959; Khan and Ansari, 1986). In theory, calculating the drag at the nodes provides damping of line motions in all cases, whereas calculating drag at the segment centers cannot provide damping for motions in which the segment centers do not translate (eg. cable vibrations having a wavelength of twice the segment length). Whether this makes any practical difference is not known. The cable tangent direction at each node point is approximated as the average of the tangent directions of the two adjacent cable elements (illustrated by the dotted lines in Figure 2). This tangent direction is necessary for calculating the hydrodynamic forces. Transverse drag and added mass are calculated using Morison's equation. Axial drag and added mass, particularly relevant for chain moorings, are calculated in a similar way. How the internal and external forces are included in the discretized formulation is described in the following subsections.

\subsection{Internal Forces}

The internal forces included in the model are axial stiffness, axial damping, and weight. Buoyancy is accounted together with weight for convenience.

The net buoyancy of each segment $i+\frac{1}{2}$ is

$$
W_{i+\frac{1}{2}}=\frac{\pi}{4} d^{2} l\left(\rho_{w}-\rho\right) g
$$

where $\rho_{w}$ is the water density and $g$ is the magnitude of acceleration due to gravity. This force is divided evenly among the two connecting nodes, giving 
the net buoyancy or weight at node $i$ in vector form as

$$
\mathbf{W}_{i}=\frac{1}{2}\left(W_{i+\frac{1}{2}}+W_{i-\frac{1}{2}}\right) \hat{\mathbf{e}}_{z}
$$

where $\hat{\mathbf{e}}_{z}$ is a unit vector in the positive $z$ direction.

The tension in cable segment $i+\frac{1}{2}$ is

$$
T_{i+\frac{1}{2}}=E \frac{\pi}{4} d^{2} \epsilon_{i+\frac{1}{2}}=E \frac{\pi}{4} d^{2}\left(\frac{\left\|\mathbf{r}_{i+1}-\mathbf{r}_{i}\right\|}{l}-1\right)
$$

where $\epsilon_{i+\frac{1}{2}}$ is the strain and the double vertical lines $(\|\cdot\|)$ denote the $L^{2}$ norm or magnitude of the vector they contain. Multiplying (3) by a unit vector pointing along the line segment gives a vector representation of the tension force:

$$
\begin{aligned}
\mathbf{T}_{i+\frac{1}{2}} & =E \frac{\pi}{4} d^{2}\left(\frac{\left\|\mathbf{r}_{i+1}-\mathbf{r}_{i}\right\|}{l}-1\right)\left(\frac{\mathbf{r}_{i+1}-\mathbf{r}_{i}}{\left\|\mathbf{r}_{i+1}-\mathbf{r}_{i}\right\|}\right) \\
& =E \frac{\pi}{4} d^{2}\left(\frac{1}{l}-\frac{1}{\left\|\mathbf{r}_{i+1}-\mathbf{r}_{i}\right\|}\right)\left(\mathbf{r}_{i+1}-\mathbf{r}_{i}\right)
\end{aligned}
$$

This tension force's direction is defined as pointing from node $i$ to node $i+1$, indicating the force on node $i$. The negative of this force vector is the force on node $i+1$. A tension force is applied only if there is positive tension in the line (i.e. if $\left\|\mathbf{r}_{i+1}-\mathbf{r}_{i}\right\|>l$ ). Otherwise, the tension force is set to zero; no compression force is modeled.

An internal damping force, which is an important contributor to numerical stability, is also applied:

$$
\mathbf{C}_{i+\frac{1}{2}}=C_{i n t} \frac{\pi}{4} d^{2} \dot{\epsilon}_{i+\frac{1}{2}}\left(\frac{\mathbf{r}_{i+1}-\mathbf{r}_{i}}{\left\|\mathbf{r}_{i+1}-\mathbf{r}_{i}\right\|}\right),
$$

where the internal damping coefficient, $C_{i n t}$, has units of stress per strain 
rate $(\mathrm{Pa}-\mathrm{s})$ and the strain rate of the segment, $\dot{\epsilon}_{i+\frac{1}{2}}$, is calculated as

$$
\begin{aligned}
\dot{\epsilon}_{i+\frac{1}{2}} & =\frac{\partial \epsilon}{\partial t}=\frac{\partial}{\partial t}\left(\frac{\left\|\mathbf{r}_{i+1}-\mathbf{r}_{i}\right\|}{l}\right) \\
& =\frac{1}{2 l} \frac{1}{\left\|\mathbf{r}_{i+1}-\mathbf{r}_{i}\right\|} \frac{\partial}{\partial t}\left[\left(x_{i+1}-x_{i}\right)^{2}+\left(y_{i+1}-y_{i}\right)^{2}+\left(z_{i+1}-z_{i}\right)^{2}\right] \\
& =\frac{1}{l} \frac{1}{\left\|\mathbf{r}_{i+1}-\mathbf{r}_{i}\right\|}\left[\left(x_{i+1}-x_{i}\right)\left(\dot{x}_{i+1}-\dot{x}_{i}\right)+\left(y_{i+1}-y_{i}\right)\left(\dot{y}_{i+1}-\dot{y}_{i}\right)+\left(z_{i+1}-z_{i}\right)\left(\dot{z}_{i+1}-\dot{z}_{i}\right)\right] .
\end{aligned}
$$

\subsection{External Forces}

The hydrodynamic analysis neglects the effect of wave kinematics, modeling the forces caused by the cable motion in quiescent water only. This is

justified later in Section 3.4. The first step in applying hydrodynamic drag and added mass models is to resolve the relative fluid velocities and accelerations over the node points into transverse and tangential components. The tangent direction, $\hat{\mathbf{q}}_{i}$, at each node is approximated as the direction of a line passing between the two adjacent node points:

$$
\hat{\mathbf{q}}_{i}=\frac{\mathbf{r}_{i+1}-\mathbf{r}_{i-1}}{\left\|\mathbf{r}_{i+1}-\mathbf{r}_{i-1}\right\|} .
$$

The transverse direction, denoted by the subscript $\mathbf{p}$ in later equations, is defined as perpendicular to $\hat{\mathbf{q}}_{i}$ and aligned with the direction of the relative water velocity over the cable. In still water, the relative water velocity over the cable node is equal to $-\dot{\mathbf{r}}_{i}$. The tangential component of this flow is given by the projection vector of $-\dot{\mathbf{r}}_{i}$ onto $\hat{\mathbf{q}}_{i}$, which is $\left(-\dot{\mathbf{r}}_{i} \cdot \hat{\mathbf{q}}_{i}\right) \hat{\mathbf{q}}_{i}$. The transverse component of the flow is then $\left(\dot{\mathbf{r}}_{i} \cdot \hat{\mathbf{q}}_{i}\right) \hat{\mathbf{q}}_{i}-\dot{\mathbf{r}}_{i}$.

The transverse hydrodynamic loads on the cable are calculated using Morison's equation, treating the cable as a slender cylindrical structure. Using the velocity components just described, the transverse drag force applied 
to node $i$ is

$$
\mathbf{D}_{\mathbf{p}_{i}}=\frac{1}{2} \rho_{w} C_{d n} d l\left\|\left(\dot{\mathbf{r}}_{i} \cdot \hat{\mathbf{q}}_{i}\right) \hat{\mathbf{q}}_{i}-\dot{\mathbf{r}}_{i}\right\|\left[\left(\dot{\mathbf{r}}_{i} \cdot \hat{\mathbf{q}}_{i}\right) \hat{\mathbf{q}}_{i}-\dot{\mathbf{r}}_{i}\right]
$$

where $C_{d n}$ is the transverse drag coefficient. Similarly, a tangential drag force to account for skin friction and form drag (eg. for chains) is calculated as

$$
\mathbf{D}_{\mathbf{q}_{i}}=\frac{1}{2} \rho_{w} C_{d t} \pi d l\left\|\left(-\dot{\mathbf{r}}_{i} \cdot \hat{\mathbf{q}}_{i}\right) \hat{\mathbf{q}}_{i}\right\|\left(-\dot{\mathbf{r}}_{i} \cdot \hat{\mathbf{q}}_{i}\right) \hat{\mathbf{q}}_{i}
$$

where $C_{d t}$ is the tangential drag coefficient.

The added mass force in the transverse direction is

$$
\mathbf{a}_{\mathbf{p}_{i}} \ddot{\mathbf{r}}_{i}=\rho_{w} C_{a n} \frac{\pi}{4} d^{2} l\left[\left(\ddot{\mathbf{r}}_{i} \cdot \hat{\mathbf{q}}_{i}\right) \hat{\mathbf{q}}_{i}-\ddot{\mathbf{r}}_{i}\right],
$$

where $C_{a n}$ is the added mass coefficient in the transverse direction and $\mathbf{a}_{\mathbf{p}_{i}}$ is the corresponding transverse added mass matrix. Similarly, a tangential added mass force, applicable for chains, is calculated as

$$
\mathbf{a}_{\mathbf{q}_{i}} \ddot{\mathbf{r}}_{i}=\rho_{w} C_{a t} \frac{\pi}{4} d^{2} l\left(-\ddot{\mathbf{r}}_{i} \cdot \hat{\mathbf{q}}_{i}\right) \hat{\mathbf{q}}_{i}
$$

where $C_{a t}$ is the tangential added mass coefficient and $\mathbf{a}_{\mathbf{q}_{i}}$ is the added mass matrix for this tangential component. Since we neglect wave kinematics, Froude-Krylov forces are not modeled.

To handle interactions with the seabed, the mooring model uses a linear spring-damper approach to represent the vertical reaction forces whenever a cable node touches the seabed. A stiffness coefficient, $k_{b}$, represents the stiffness per unit area of the seabed. A damping coefficient, $c_{b}$, represents the viscous damping per unit area. The model is only active when a node contacts the seabed (i.e. when $z_{i} \leq z_{\text {bot }}$ ). When that conditions is true, the force due to the interaction is modeled as

$$
\mathbf{B}_{i}=d l\left[\left(z_{b o t}-z_{i}\right) k_{b}-\dot{z}_{i} c_{b}\right] \hat{\mathbf{e}}_{z}
$$


For this work, we did not model horizontal friction from contact with the seabed. While this can be incorporated without great difficulty, it is not of critical importance for modeling the interaction of the mooring chain with the smooth concrete floor of the wave basin for the system described in Section 3.

\subsection{Mass and Integration}

In the lumped-mass formulation, the mass of the cable is discretized into point masses at each node by assigning each node half the mass of each of the two adjacent cable segments. The $3 \times 3$ mass matrix for node $i$ can be expressed as

$$
\mathbf{m}_{i}=\frac{\pi}{4} d^{2} l \rho \mathbf{I}
$$

where $\mathbf{I}$ is the identity matrix.

The added mass, which is proportional to $\ddot{\mathbf{r}}_{i}$, also needs to be included in the mass matrix. Rearranging (10) and (11) to factor out $\ddot{\mathbf{r}}_{i}$ and reversing signs to move the terms to the left-hand side of an equation $m a=f$ gives the added mass matrix for node $i$ :

$$
\mathbf{a}_{i}=\mathbf{a}_{\mathbf{p}_{i}}+\mathbf{a}_{\mathbf{q}_{i}}=\rho_{w} \frac{\pi}{4} d^{2} l\left[C_{a n}\left(\mathbf{I}-\hat{\mathbf{q}}_{i} \hat{\mathbf{q}}_{i}^{\top}\right)+C_{a t}\left(\hat{\mathbf{q}}_{i} \hat{\mathbf{q}}_{i}^{\top}\right)\right]
$$

The complete equation of motion for each node $i$ is:

$\underbrace{\left[\mathbf{m}_{i}+\mathbf{a}_{i}\right]}_{\text {mass and added mass }} \quad \ddot{\mathbf{r}}_{i}=\underbrace{\mathbf{T}_{i+\frac{1}{2}}-\mathbf{T}_{i-\frac{1}{2}}+\mathbf{C}_{i+\frac{1}{2}}-\mathbf{C}_{i-\frac{1}{2}}}_{\text {internal stiffness and damping }}+\underbrace{\mathbf{W}_{i}+\mathbf{B}_{i}}_{\text {weight and contact }}+\underbrace{\mathbf{D}_{\mathbf{p}_{i}}+\mathbf{D}_{\mathbf{q}_{i}}}_{\text {drag }}$

The second-order system of ordinary differential equations represented in (15) can be easily reduced to a system of first-order differential equations. 
These are then solved using a constant-time-step second-order Runge-Kutta (RK2) integration algorithm.

\subsection{Coupling with FAST}

We use two implementations of the mooring model in this study. One standalone version drives the fairlead motions based on platform motions read in from a text file. The other, compiled in the form of a dynamicallylinked library (DLL), allows coupling with NREL's FAST version 7 simulator (Jonkman, 2007). In either case, the mooring system properties are described by a plain text input file similar in form to that used by the open-source quasi-static mooring model MAP (Masciola et al., 2013a).

The coupling between the lumped-mass mooring model and the FAST simulator follows a loose-coupling arrangement, as defined in Jonkman (2013) and used previously in Hall et al. (2014). Whereas FAST is run with the widely-used time step of $12.5 \mathrm{~ms}$, the mooring model uses a shorter time step of $1.25 \mathrm{~ms}$ to ensure stability of the RK2 integrator. At the start of each FAST time step, FAST transmits the platform position and velocity to the mooring model. The mooring model then calculates the fairlead kinematics and solves for the line dynamics over the duration of the FAST time step (entailing ten mooring time steps). Finally, the resulting mooring forces are transmitted back to FAST to be used in FAST's dynamics solver. This process is diagrammed in Figure 3.

The coupling required a number of changes to the FAST source code to accommodate a new subroutine that interacts with the mooring model DLL in place of the default quasi-static mooring subroutine. With these changes, FAST can be run with the new mooring line model by simply switching the 
mooring line options flag in the platform input file and adding a new input file describing the mooring line properties. The initial conditions for the mooring line model, in terms of node positions, are set using the quasi-static mooring line model of FAST.

\section{DeepCwind Semisubmersible Model Description}

To validate the lumped-mass mooring line model, we used the DeepCwind semisubmersible design since it has been widely studied through both experiments and simulations. The design features a $5 \mathrm{MW}$ horizontal-axis wind turbine atop a three-column semisubmersible platform with a smaller fourth central column. The outer columns feature heave plates, and station keeping is provided by three slack catenary chain moorings.

The DeepCwind semisubmersible design has had several incarnations, including a 1:50-scale model tested in 2011 (Goupee et al., 2012), a refined 1:50-scale model tested in 2013 (Goupee et al., 2014), and a set of full-scale specifications used for numerical modeling in the Offshore Code Comparison Collaboration Continuation (OC4) project (Robertson et al., 2014a). This last version is referred to as the OC4-DeepCwind semisubmersible and has been analyzed widely (Robertson et al., 2014b).

The version considered in this work is the original 1:50-scale model that was tested at Maritime Research Institute Netherlands (MARIN) in 2011. This incarnation has many similarities to the OC4-DeepCwind specifications; the main difference is that the scale model features a turbine that is modeled after, but slightly different from, the NREL 5 MW reference turbine used in the OC4 project. The 2011 DeepCwind semisubmersible model is shown in 
Figure 4. Table 1 lists the sea states from that test campaign that are used in this study, characterized by wave height $(H)$ and period $(T)$ for regular waves and significant wave height $\left(H_{s}\right)$ and peak spectral period $\left(T_{p}\right)$ for irregular waves. The table also provides the calculated mean viscous drift force $\left(F_{v i s c .}\right)$ described later in Section 3.2.

A number of studies have looked at developing and validating numerical models from the test results, including the wind turbine performance by Martin et al. (2012) and the platform hydrodynamics by Coulling et al. (2013b). More details about those aspects of the design and their modeling is available in those references. The remainder of this section will go over the general characteristics of the design and then describe in more detail the numerical modeling techniques we used for the platform and mooring system. All quantities, including those from the test results, are presented at full scale.

\subsection{Wind Turbine}

For this work, we modeled the turbine using the physical and aerodynamic properties it possessed for the 2011 test campaign. The upwind, three-bladed wind turbine is similar to the NREL 5 MW reference turbine (Jonkman et al., 2009) used in the OC4-DeepCwind design, having an identical rotor diameter (126 m) and hub height $(90 \mathrm{~m})$, but the 1:50-scale model has an increased nacelle mass due to instrumentation requirements. Table 2 summarizes the gross properties of the wind turbine and further details are available in Martin (2011). Additional deviations from the NREL reference design are that the blade pitch angle was set to 6.4 degrees in the operational wind cases and increased wind speeds and slightly elevated rotor RPMs were used. As 
described by Martin (2011), these changes were necessary in order to reproduce full-scale thrust characteristics in the low-Reynolds number conditions of the Froude-scaled test environment.

To match these aerodynamic characteristics in simulations, a description of the wind turbine was created for FAST by analyzing the low Reynolds number airfoil characteristics in XFOIL (Drela, 1989), processing the results in NREL's AirfoilPrep tool, and using a multi-objective genetic algorithm technique to tune the results, as detailed in Coulling et al. (2013b). That aerodynamic description is what we used for the simulations in this study.

In terms of structural properties, the rotor blades used in the tests were very rigid compared to the full scale design; accordingly, rotor blade bending

degrees of freedom are disabled in the simulations. Deflections of the tower were not negligible and finite-element analysis of the tower suggested the use of 9th-order mode shapes for the tower bending modes. Accordingly, these higher-order modal characteristics, described by Coulling et al. (2013b), were implemented in FAST.

\subsection{Floating Platform}

The platform characteristics used in this study are identical to those of the OC4-DeepCwind semisubmersible design except for slight differences in mass and center of mass to account for the different turbine mass. The platform consists of four cylinders with a draft of $20 \mathrm{~m}$. The central cylinder has a diameter of $6.5 \mathrm{~m}$ and supports the wind turbine. The outer three cylinders have a diameter of $12 \mathrm{~m}$ except for the bottom $6 \mathrm{~m}$ portion, which has an enlarged diameter of $24 \mathrm{~m}$, serving as a heave plate. The outer cylinders are spaced at a distance of $40.87 \mathrm{~m}$ from the platform centerline. The cylinders 
are connected by $1.6 \mathrm{~m}$ diameter cross bracing. The mass characteristics of the platform, described about its center of mass $(\mathrm{CM})$, are provided in Table 3. Further details about the platform are available in Robertson et al. (2014a).

In previous model validation work, Coulling et al. (2013a,b) modeled the platform hydrodynamics by supplementing FAST's default linear hydrodynamics approach with quadratic damping coefficients in each of the six platform degrees of freedom and later included the effects of second-order difference-frequency forces using Newman's approximation. The model used in this study builds on that previous work, using the same quadratic damping coefficients (given in Table 4) but extending the hydrodynamics to include full second-order wave excitation forces and a viscous mean drift force in surge.

Sum-frequency and difference-frequency second-order wave excitation loads are calculated following the method of Gueydon et al. (2014). An additional source of mean drift is noticeable in the test results, which prompted the inclusion of viscous mean drift forces in the modeling. The viscous contribution to mean drift force in surge is calculated following DNV-RP-C205 (DNV, 2007). For cylinders in regular waves, the force is proportional to wavenumber $(k)$, diameter $(D)$, and the cube of wave amplitude $(A)$ :

$$
F_{\text {visc. }}=\frac{2}{3 \pi} \rho g k C_{d} D A^{3} .
$$

This equation is applied to each of the four columns of the platform. To be comparable with the experimental results, we set the drag coefficient to 1.2, consistent with the model-scale Reynolds number. For irregular waves, to obtain a crude mean drift force, we used (16) with half the significant 
wave height substituted for $A$ and the peak period used to calculate $k$. The viscous drift force calculated for each sea state is shown in Table 1.

\subsection{Mooring System Static Properties}

In the 1:50-scale tests, the semisubmersible was moored by three chains of approximately $835 \mathrm{~m}$ length (full scale) to anchor points at a radius of $837.6 \mathrm{~m}$ from the platform centerline. The water depth was $200 \mathrm{~m}$. Based on measurements of a sample of chain used in the tests, Table 5 gives the properties of the mooring chain used in the tests, after scaling to full scale. Given the present focus on mooring modeling, these properties are refined from those reported by Coulling et al. (2013b). While the data provided accurately describes the studless chain used for testing, they do not conform exactly to a commercially-available chain size. The cable diameter, $d$, discussed in Section 2 should be considered a volume-equivalent diameter for the mooring chain - the diameter of a cylindrical cable having the same displacement per unit length as the chain.

The quasi-static mooring line model from FAST (Jonkman, 2007) provides a reference with which to verify the steady-state performance of the lumped-mass mooring model. Figure 5 shows the fairlead tension and line angle predicted by the lumped-mass model for different levels of discretization, normalized by the value predicted by the quasi-static model. The unevenness of the tension curve is likely due to the discrete handling of seabed contact, in which the number and position of the touchdown node changes inconsistently between different discretization levels. Both the tension and

the angle are well within $1 \%$ of the quasi-static value at a discretization of 20 elements. Accordingly, we used 20 elements for each mooring line in the 
following analyses. At this level of discretization, use of the lumped-mass mooring model typically increases the simulation time by $10-15 \%$ compared to a normal FAST simulation with the quasi-static mooring model.

In this study, we slightly adjusted the unstretched line lengths reported in previous work (Coulling et al., 2013b) in order to better match the line pretensions measured in the experiments. These pretensions are not quite equal, hence each line has a different unstretched length, as indicated in Table 6. Tension results are shown from both lumped-mass (LM) and quasi-static (QS) models.

\subsection{Mooring System Hydrodynamic Properties}

Since the mooring model is formulated for cylindrical elements, the drag and added mass coefficients used for hydrodynamic force calculations need to be adjusted to account for the use of a chain mooring. To begin with, we selected a transverse drag coefficient of 2.0 in accordance with the recommendations for scale-model chains in DNV-RP-F205 (DNV, 2004). This value is based on the chain's nominal diameter (the diameter of the bar that composes each chain link). Scaling by the ratio of the nominal diameter to the volume-equivalent diameter $(0.0779 / 0.13376)$ gives the equivalent drag coefficient required by the model. In addition, the chain used in the tests is of a more slender proportion than the standard dimensions the recommended drag coefficients are meant to reflect. Therefore, we scaled the drag coeffi-

cient to account for the reduced frontal area per unit length $\left(A_{L}\right)$. The final transverse drag coefficient provided to the model is

$$
C_{d n}=C_{d} \frac{A_{L, \text { test }}}{A_{L, \text { typical }}} \frac{D}{d}=2.0\left(\frac{0.2296}{0.2470}\right)\left(\frac{0.0779}{0.13376}\right)=1.08,
$$


where, for the sake of determining the scaling ratio, $A_{L}$ is approximated using the frontal area of a chain link oriented normal to the flow:

$$
A_{L} \approx \frac{(2 L+2 \pi R) D}{L+2 R-D} .
$$

The tangential drag coefficient is based on the value of 1.15 recommended for studless chain in DNV-OS-E301 (DNV, 2013). Scaling for the equivalent diameter formulation of the model and dividing by $\pi$ gives $C_{d t}=0.213$. No chain shape correction was made to this coefficient since the overlap of links makes identifying the proper frontal area for axial drag calculations ambiguous and its bearing on the line tensions is significantly less than that of the transverse drag. We calculated added mass coefficients in both transverse and tangential directions by applying the theoretical coefficient of 1.0 for cylinders in transverse flow, as given in DNV-RP-C205 (DNV, 2007), to the chain link geometry. This gives $C_{a n}=0.865$ and $C_{a t}=0.269$.

The suitability of the four hydrodynamic coefficients can be seen by comparing the fairlead tensions measured in the model tests with those calculated by the lumped-mass model when the fairlead is moved according to the test data. Figure 6 shows this comparison for the tension of fairlead 1, the upwind fairlead, during a regular wave case. The shaded areas indicate the sensitivity of the fairlead tension to the four different hydrodynamic coefficients. The upper and lower bounds of the shaded regions correspond to $\pm 50 \%$ variations of each of the four hydrodynamic coefficients. It can be seen that the simulation (labeled "LM") closely matches the test data (labeled "test") and that the fairlead tensions are most sensitive to the transverse drag coefficient.

Figure 6 also shows, between $300 \mathrm{~s}$ and $320 \mathrm{~s}$, how the inclusion of wave kinematics in the drag calculations affects the fairlead tension. In this 
case, including wave kinematics increases the tensions on fairlead 1, which is aligned with the wave propagation direction, by just over $3 \%$. The change in tensions on fairleads 2 and 3 is less than $1 \%$. This is a conservative indication since regular wave case 5 can be expected to have the greatest wave particle velocities of all the regular wave cases. Accordingly, for the mooring system and load cases in this study we conclude that wave kinematics can be neglected without having a large impact on the results. This is fortunate since accounting for wave kinematics would add considerable complexity to the process of matching the experimental conditions, especially for irregular sea states.

The effect of discretization on the line dynamic response is also worth considering. Figure 7 shows that using 20 segments per mooring line gives convergent results. For this level of discretization, an internal damping coefficient of $C_{i n t}=100 \mathrm{MPa}$-s reduces high-frequency tension vibrations not seen in the test data without affecting the gross tension amplitudes.

For bottom contact modeling, the spring-damper coefficients used in the analysis are stiffness $k_{b}=3 \mathrm{MPa} / \mathrm{m}$ and damping $c_{b}=300 \mathrm{MPa}-\mathrm{s} / \mathrm{m}$. These are sufficient to ensure that sinking and bouncing of nodes on the seabed is negligible.

\section{Uncoupled Lumped-Mass Mooring Model Validation}

The first set of validation results focuses on comparing only the mooring line behavior between the model predictions and the test data. By using the platform motions from the test data to prescribe the fairlead motions in the mooring model, the performance of the model can be studied in isolation. 
The platform motions during testing were measured by an NDI Certus optical motion tracking system using three LEDs on the platform. Filtering of the platform motion data was necessary to remove measurement noise that would otherwise cause severe and unrealistic line tension fluctuations. We used a fourth-order Butterworth low-pass filter with cutoff frequency of $0.5 \mathrm{~Hz}$. A sample of the platform motions before and after filtering is shown in Figure 8.

The following subsections show simulation results and test data for both regular and irregular sea states. Results from FAST's quasi-static model, also with prescribed fairlead motions, are included for comparison.

\subsection{Regular Waves}

For regular wave cases, the mooring line tensions predicted by the lumpedmass model match the experimental data quite well, in terms of both magnitudes and phases. Figure 9 shows a portion of the fairlead tension responses for regular wave 5, comparing those measured in the tests, those predicted by the lumped-mass mooring model, and those predicted by FAST's default quasi-static mooring model. Good agreement in amplitudes between the lumped-mass model and the test data is evident, as is the large amplitude underprediction by the quasi-static model. Figure 10 shows the corresponding power spectral density (PSD) plots of these fairlead tensions. The large peaks at $0.083 \mathrm{~Hz}$ correspond to the wave excitation frequency, and peaks are also visible at multiples of this frequency. Good agreement at the first and second peaks can be observed between the lumped-mass model and the test data, although the model predicts higher levels of excitation between the peaks. The quasi-static model undepredicts the excitation across the 
spectrum.

Fairlead tension response amplitude operators (RAOs), providing tension amplitudes and phases, are calculated based on sine-wave fits to the tension time series results. Table 7 summarizes how the fairlead tension RAOs predicted by the lumped-mass and quasi-static mooring line models compare with the RAOs of the test data across all 7 regular wave cases. Figure 11 provides a visual comparison of the RAO magnitudes between the test data and the simulations. Agreement tends to improve with increasing wave amplitude. The level of disagreement ranges from up to $90 \%$ tension overprediction and $15^{\circ}$ phase error in regular wave 1 to less than $8 \%$ tension error and $7^{\circ}$ phase error for regular waves 5,6 , and 7 . It seems likely that at smaller wave amplitudes, the lower signal-to-noise ratio in the platform motion data causes the measurement noise to have a larger effect on the simulated mooring line tensions. The phase difference compared to the test data is below $10^{\circ}$ for the lumped-mass model in most cases, while it is consistently over $45^{\circ}$ for the quasi-static model.

Regular wave 7 provides a good case for studying snap loads, with line 1, the upwind mooring, losing tension with every wave. Figure 12 shows the fairlead 1 tension time series for this case, comparing the quasi-static and lumped-mass model predictions with the test data. The lumped-mass model predicts the onset of the slack condition very well, although it lags a bit in the tension recovery. The quasi-static model on the other hand neither matches the tension cycle amplitude nor predicts the slack condition. 


\subsection{Irregular Waves}

To look at the mooring model performance in irregular wave conditions, we prescribed fairlead motions from a test case with the design sea state and dynamic wind. As given in Table 1, the design wave is defined by a 10.5 $\mathrm{m}, 14.3 \mathrm{~s}$ JONSWAP spectrum. The dynamic wind is based on a National Petroleum Directorate (NPD) spectrum (API, 2007) with a mean hub-height speed of $19.6 \mathrm{~m} / \mathrm{s}$, standard deviation of $2.04 \mathrm{~m} / \mathrm{s}$, and wind shear exponent of 0.0912. As explained by Coulling et al. (2013b), these simulation values are chosen to match the experimental wind field.

Figure 13 compares the predicted fairlead tensions with those of the test data. The lumped-mass model matches the fairlead tensions very well in terms of phase and moderately well in terms of amplitude. The model captures the snap load events in line 1 occurring after $4770 \mathrm{~s}$. In contrast, the quasi-static model has large disagreement from the test results in both amplitude and phase, and does not give any sign of the snap loads. Figure 14 shows the corresponding PSD plots. Agreement between model and test data is relatively good. There is a small overprediction of excitement in fairleads 2 and 3 around $0.4 \mathrm{~Hz}$. A large peak in fairlead 3 around $1.2 \mathrm{~Hz}$ in the test data only is consistent with the higher-frequency oscillations visible in that channel in many of the test data time series; its presence only in fairlead 3 suggests it is an artifact of the experimental setup rather than a representation of the true mooring line dynamics.

The difference between the two models is also evident in the fairlead fatigue loads predicted for this same design wave and dynamic wind case. Table 8 gives the damage-equivalent and extreme loads calculated by NREL's 
MLife tool (Hayman and Buhl, 2012) for each fairlead connection using the two models. These calculations assume an $\mathrm{S} / \mathrm{N}$ curve slope of $m=3$ and essentially infinite ultimate strength, consistent with the methodology described by Matha (2009). The table shows that the values predicted by the lumped-mass model agree to within $10 \%$ of the test data, except for the fairlead 1 extreme load whose disagreement is slightly larger. Meanwhile, the quasi-static model underpredicts the extreme loads by $10-25 \%$ and the fatigue loads by $65-75 \%$.

In summary, the above results of the lumped-mass mooring model in regular and irregular conditions show consistently close agreement with the fairlead tensions in the test data. Fairlead tension RAOs, maximums, and fatigue loads are in most cases predicted to within $10 \%$ of the experimental values. Furthermore, the model predicts snap loads reliably. This indicates that the dynamic phenomena affecting catenary chain mooring systems are represented well in the lumped-mass model.

\section{Coupled Floating Wind Turbine Model Validation}

Assessing the lumped-mass mooring model's value as a design tool requires performing validation of a coupled model of the full floating wind turbine system. We did this by coupling the lumped-mass model to FAST, as described in Section 2.4. The environmental conditions in FAST must be matched to those used in the experiments. This was done using the time series of calibrated wave elevations and wind speed measurements from the MARIN tests, taking care to observe correct synchronization between each. 


\subsection{Regular Waves}

Applying the coupled simulation capability to regular wave cases provides an indication of which aspects of the numerical models match the test data well and which need further improvement. We analyzed regular wave cases 1 through 7 in the absence of wind using FAST with both the lumpedmass mooring model and the default quasi-static model. The wave loadings applied to the platform include second-order and viscous-drift components, as described in Section 3.2.

Figure 15 shows a sample of the platform motion and fairlead tension time series from the regular wave 5 case with no wind. The platform motions are based on a coordinate system located at the mean water line. It can be seen that the choice of mooring model has at most a small impact on the platform motions. The pitch response predicted by the simulations matches the test data well, but surge and heave motions are underpredicted. The heave motion has the greatest disagreement, with the simulations underpredicting the amplitude by $26 \%$ and leading in phase by $40^{\circ}$. This was observed in other regular wave cases as well. Not surprisingly, the fairlead tensions predicted by the lumped-mass mooring model show similar disagreements with the data: namely, underpredicting the amplitude and having some phase lead. An additional observation about the lumped-mass model results is the presence of tension pulses during the low-tension phase of the response in fairleads 2 and 3 which are not seen in the test data. Evidence of similar pulses, albeit at different phases, is observable in other cases as well, including in the uncoupled results shown in Figures 9 and 13. Their cause is unknown. 
Figure 16 compares the predicted platform motion RAO magnitudes in surge, heave, and pitch with those of the test data. Figure 17 compares the corresponding fairlead tension RAO magnitudes. The fairlead tension responses predicted by the lumped-mass model are in general somewhat less than those of the test data and also those predicted by the uncoupled simulations (shown in Figure 11). The heave RAO magnitudes are similarly underpredicted, regardless of the mooring model, suggesting that the fairlead tension underprediction is a result of the heave underprediction.

\subsection{Irregular Waves}

In developing the coupled simulations, we considered which model components are necessary to represent the platform hydrodynamics. Since the present focus is on mooring modeling and a hydrodynamic platform model was developed in previous work, the hydrodynamic characteristics described by Coulling et al. (2013a) were not modified but only complemented with additional terms: full second-order wave forces and viscous mean drift forces as described in Section 3.2. These additions were warranted because of the importance of platform drift to the mooring tensions. Figure 18 shows the effect including these components has on the surge motion of the platform in operational wave 2 without wind (using the quasi-static mooring line model). As can be seen, there is a noticeable difference in mean surge between the test results and the simulation with only linear hydrodynamics. Including the second-order hydrodynamics corrects for roughly half of this difference; the additional drift forcing provided by the viscous mean drift model of (16) is needed to make up the rest of the difference. The effect of second-order forces on the response in other degrees of freedom is relatively small. 
To illustrate the performance of the coupled model in stochastic environmental conditions, Figure 19 shows platform motion and fairlead tension time series for the same case as used in Section 4.2: the design sea state (10.5 m, 14.3 s JONSWAP spectrum) and NPD wind spectrum with mean hubheight speed of $19.6 \mathrm{~m} / \mathrm{s}$. In this case, the turbine operates with a constant speed of 12.73 RPM. For the most part, the platform motions show some agreement in the amplitudes and phases around the peak wave excitation frequency. However, the heave response shows consistent underprediction of the response amplitude and also some phase differences, regardless of the mooring model.

Looking at the corresponding fairlead tensions, the lumped-mass model generally underpredicts the tension response amplitudes compared to the test data. For fairleads 2 and 3, the tension fluctuations are relatively small and signs of agreement with the test data are only evident during times of larger tension amplitude. For fairlead 1, the tension amplitudes are larger and some agreement in phases can be seen. Several snap load events are visible in the test data beginning at $t=4772 \mathrm{~s}$. The lumped-mass model predicts reduced tensions at these times but, unlike in the uncoupled results, it does not predict the fully slack condition. As with the regular wave results, the fairlead tension response underprediction seems to correspond with underpredicted platform heave response. In all cases, the quasi-static mooring line model underpredicts the mooring tension response amplitudes to a greater degree.

Table 9 gives the damage-equivalent and maximum fairlead loads calculated for the same test case, using the same fatigue parameters as in Section 4.2. The evident underprediction of both fatigue and extreme line loads 
matches the amplitude differences visible in the time series of Figure 19.

In general, the coupled results show an underprediction of fairlead tension response amplitudes. This seems to be a result of underpredicted heave response, since tension agreement was good in Section 4 where the fairlead motions were prescribed. The heave underprediction is similar to that observed by Koo et al. (2014), which was attributed to the presence of a cancellation frequency phenomenon, where diffraction and Froude-Krylov wave excitation forces cancel, in a diffraction-based analysis. Using a linear hydrodynamics approach combined with global viscous damping coefficients based only on absolute platform motions neglects viscous wave forces on the heave plates and truss members, thereby significantly underpredicting the wave excitation in the heave direction. This explanation is corroborated by the findings of the OC4 project (Robertson et al., 2014b), which concluded that using only a global drag matrix to represent viscous loads may be inadequate, especially in large waves. In fact, the OC4 findings suggest that a Morison-based approach to the platform hydrodynamics may give better results than an approach using only linear hydrodynamics. In sum, there are clear indications of how changes to the platform model could improve the coupled results. While outside the scope of this study, they are an important pointer for future work.

\section{Conclusions}

This project saw the creation and verification of a lumped-mass mooring line model suitable for use in floating wind turbine simulation. By neglecting bending and torsional stiffnesses, the model captures the main dynamic be- 
haviors affecting catenary chain mooring lines of floating wind turbines while reducing computational cost compared to higher-fidelity mooring models.

We validated the model against experimental results from the DeepCwind semisubmersible in uncoupled form and in coupled form with FAST. For the uncoupled validation, in which the fairlead kinematics are prescribed based on the test data, the fairlead tensions predicted by the lumped-mass model agree well with the experiment data. In the larger regular wave cases which are less impacted by measurement noise, fairlead tension response amplitudes match the test data within $8 \%$ and phases match within $7 \%$. In the irregular wave case considered, modeled extreme and fatigue loads are within $10 \%$ of the test data values. Snap load conditions are predicted consistently. A quasi-static model is unable to produce comparable results or predict snap loads.

In coupled simulations of the entire floating wind turbine system, the platform surge and pitch motions predicted using either mooring model agree well with the test data, but the platform heave motions are somewhat underpredicted. Consequently, fairlead tension loads are also underpredicted, by as much as $50 \%$ with the lumped-mass model, and snap load events are not consistently detected. The good fairlead tension agreement in the uncoupled comparisons but poor agreement when the whole system is simulated suggest that the major shortcoming of the coupled simulation is the platform hydrodynamics, not the mooring model. This correlation between heave motion underprediction and mooring load underprediction is consistent with the findings of Koo et al. (2014). In addition, the results show that whether the mooring loads are computed by a quasi-static model or a dynamic mooring 
model has at most a small influence on the platform motions of the DeepCwind semisubmersible. This is further evidence that the poor mooring load predictions are caused by the poor platform heave predictions and not the other way around. In any case, even with the platform motion discrepancies, the mooring loads predicted by the lumped-mass model are considerably closer to the test data than those predicted by the quasi-static model.

While reliably predicting the mooring line loads, the lumped-mass model adds little computational cost to the simulation. In FAST simulations conducted in this work, using the lumped-mass model rather than the quasistatic model increased the computation time by $10-15 \%$.

Future work with the lumped-mass mooring line model is focused on refining the source code in preparation for making it publicly available, creating an interface for Matlab/Simulink, and recreating the model in FORTRAN for integration with FAST version 8 (Jonkman, 2013). To match the convention used by other FAST modules, these developments are proceeding under the name MoorDyn.

\section{Acknowledgments}

Thanks are due to Marco Masciola for providing advice on a variety of issues related to mooring modeling, Jason Jonkman for providing second-

order hydrodynamics data files and general input, Tiago Duarte for helping with the details of calculating second-order wave excitation forces, and Chris Allen for input on drag coefficient selection. Thanks to Krish Thiagarajan for providing the Fluid-Structure Interaction class that prompted initial development of the lumped-mass model. Thanks to Habib Dagher for his leadership 
in making the DeepCwind test campaign a reality. The test data was provided by the DeepCwind Consortium through DOE grants DE-EE0002981 and DE-EE0003728, NSF grant IIP-0917974, and the University of Maine. Scholarship support from the Natural Sciences and Engineering Research Council of Canada is gratefully acknowledged.

\section{References}

API, 2007. API RP 2A-WSD: Recommended practice for Planning, Designing and Constructing Fixed Offshore Platforms - Working Stress Design. Technical Report. American Petroleum Institute.

Azcona, J., Nygaard, T.A., Munduate, X., Merino, D., 2011. Development of a code for dynamic simulation of mooring lines in contact with seabed, in: EWEA Offshore 2011, Amsterdam, The Netherlands.

Bae, Y., Kim, M., Im, S., Chang, I., 2011. Aero-Elastic-Control-FloaterMooring coupled dynamic analysis of floating offshore wind turbines, in: Proceedings of the Twenty-first (2011) International Offshore and Polar Engineering Conference, Maui, Hawaii, USA.

Buckham, B.J., 2003. Dynamics modelling of low-tension tethers for submerged remotely operated vehicles. PhD thesis. University of Victoria. Canada.

Coulling, A.J., Goupee, A.J., Robertson, A.N., Jonkman, J.M., 2013a. Importance of second-order difference-frequency wave diffraction forces in the validation of a fast semi-submersible floating wind turbine model, in: Pro- 
ceedings of the ASME 2013 32nd International Conference on Ocean, Offshore, and Arctic Engineering, Nantes, France.

Coulling, A.J., Goupee, A.J., Robertson, A.N., Jonkman, J.M., Dagher, H.J., 2013b. Validation of a FAST semi-submersible floating wind turbine numerical model with DeepCwind test data. Journal of Renewable and Sustainable Energy 5, 023116:1-29.

DNV, 2004. DNV-RP-F205: Global Performance Analysis of Deepwater Floating Structures. Technical Report. Det Norske Veritas. Høvik, Norway.

DNV, 2007. DNV-RP-C205: Environmental conditions and environmental loads. Technical Report. Det Norske Veritas. Høvik, Norway.

DNV, 2013. DNV-OS-E301: Position Moorings. Technical Report. Det Norske Veritas. Høvik, Norway.

Drela, M., 1989. XFOIL: an analysis and design system for low reynolds number airfoils, in: Conference on Low Reynolds number Aerodynamics, University of Notre Dame, USA.

Garrett, D.L., 1982. Dynamic analysis of slender rods. Journal of Energy Resources Technology 104, 302-306.

Goupee, A., Fowler, M., Kimball, R., Helder, J., de Ridder, E., 2014. Additional Wind/Wave basin testing of the DeepCwind Semi-Submersible with a Performance-Matched wind turbine, in: Proceedings of the 33rd International Conference on Ocean, Offshore and Arctic Engineering, San Francisco, California, USA. 
Goupee, A., Koo, B., Lambrakos, K., Kimball, R., 2012. Model tests for three floating wind turbine concepts, in: Proceedings of Offshore Technology Conference (OTC 2012), Houston, Texas, USA.

Gueydon, S., Duarte, T., Jonkman, J., 2014. Comparison of Second-Order loads on a semisubmersible floating wind turbine, in: Proceedings of the 33rd International Conference on Ocean, Offshore and Arctic Engineering, ASME, San Francisco, California, USA.

Hall, M., Buckham, B., Crawford, C., 2014. Evaluating the importance of mooring line model fidelity in floating offshore wind turbine simulations. Wind Energy 17, 1835-1853.

Hayman, G., Buhl, M.L., 2012. MLife User's Guide for Version 1.00. Technical Report. National Renewable Energy Laboratory. Golden, Colorado, USA.

Huang, S., 1994. Dynamic analysis of three-dimensional marine cables. Ocean Engineering 21, 587-605.

Jonkman, J.M., 2007. Dynamics Modeling and Loads Analysis of an Offshore Floating Wind Turbine. PhD thesis. University of Colorado at Boulder. USA.

Jonkman, J.M., 2013. The new modularization framework for the FAST wind turbine CAE tool, in: 51st AIAA Aerospace Sciences Meeting and 31st ASME Wind Energy Symposium, American Institute of Aeronautics and Astronautics, Grapevine, Texas, USA. 
Jonkman, J.M., Butterfield, S., Musial, W., Scott, G., 2009. Definition of a 5MW Reference Wind Turbine for Offshore System Development. Technical Report 38060. National Renewable Energy Laboratory. Golden, Colorado, USA.

Kallesoe, B.S., Hansen, A.M., 2011. Dynamic mooring line modeling in Hydro-Aero-Servo-Elastic wind turbine simulations, in: Proceedings of the Twenty-first International Offshore and Polar Engineering Conference, Maui, Hawaii, USA.

Khan, N.U., Ansari, K.A., 1986. On the dynamics of a multicomponent mooring line. Computers \& Structures 22, 311-334.

Koo, B., Goupee, A.J., Lambrakos, K., Lim, H., 2014. Model test data correlations with fully coupled Hull/Mooring analysis for a floating wind turbine on a Semi-Submersible platform, in: Proceedings of the 33rd International Conference on Ocean, Offshore and Arctic Engineering, San Francisco, California, USA.

Malahy, R.C., 1985. A nonlinear finite element method for the analysis of the offshore pipelaying problem. Thesis. Rice University. Houston, Texas, USA.

Martin, H., 2011. Development of a Scale Model Wind Turbine for Testing of Offshore Floating Wind Turbine Systems. MS thesis. University of Maine. Orono, Maine, USA.

Martin, H.R., Viselli, A.M., Kimball, R.W., Goupee, A.J., 2012. Methodology for Wind/Wave basin testing of floating offshore wind turbines, in: 
Proceedings of the 31st International Conference on Ocean, Offshore and Arctic Engineering, Rio de Janeiro, Brazil.

Masciola, M., Jonkman, J., Robertson, A., 2013a. Implementation of a multisigmented, Quasi-Static cable mode, in: Proceedings of the Twenty-third (2013) International Offshore and Polar Engineering Conference, Anchorage, Alaska, USA.

Masciola, M., Robertson, A., Jonkman, J., Coulling, A., Goupee, A., 2013 b. Assessment of the importance of mooring dynamics on the global response of the DeepCWind floating semisubmersible offshore wind turbine, in: Proceedings of the Twenty-third (2013) International Offshore and Polar Engineering Conference, Anchorage, Alaska, USA.

Matha, D., 2009. Model Development and Loads Analysis of an Offshore Wind Turbine on a Tension Leg Platform, with a Comparison to Other Floating Turbine Concepts. PhD thesis. University of Colorado - Boulder. USA.

Matha, D., Bischoff, O., Fechter, U., Kuhn, M., 2011. Non-Linear MultiBody mooring system model for floating offshore wind turbines, in: EWEA Offshore 2011, Amsterdam, The Netherlands.

McNamara, J.F., O'Brien, P.J., Gilroy, S.G., 1988. Nonlinear analysis of flexible risers using hybrid finite elements. Journal of Offshore Mechanics and Arctic Engineering 110, 197-204.

Palm, J., Moura Paredes, G., Eskilsson, C., Taveira Pinto, F., Bergdahl, L., 2013. Simulation of mooring cable dynamics using a discontinuous galerkin 
method, in: Proceedings of V International Conference on Computational Methods in Marine Engineering, Hamburg, Germany.

Robertson, A., Jonkman, J., Masciola, M., Song, H., Goupee, A., Coulling, A., Luan, C., 2014a. Definition of the Semisubmersible Floating System for Phase II of OC4. NREL Technical Report TP-5000-60601. National Renewable Energy Laboratory. Golden, Colorado, USA.

Robertson, A., Jonkman, J., Vorpahl, F., Popko, W., Qvist, J., Frøyd, L., Chen, X., Azcona, J., Uzunoglu, E., Guedes Soares, C., Luan, C., Yutong, H., Pengcheng, F., Yde, A., Larsen, T., Nichols, J., Buils, R., Lei, L., Nygaard, T.A., Manolas, D., Heege, A., Vatne, S.R., Ormberg, H., Duarte, T., Godreau, C., Hansen, H.F., Nielsen, A.W., Riber, H., Le Cunff, C., Beyer, F., Yamaguchi, A., Jung, K.J., Shin, H., Shi, W., Park, H., Alves, M., Guérinel, M., 2014b. Offshore code comparison collaboration continuation within IEA wind task 30: Phase II results regarding a floating semisubmersible wind system, in: Proceedings of the 33rd International Conference on Ocean, Offshore and Arctic Engineering, San Francisco, California, USA.

Walton, T.S., Polachek, H., 1959. Calculation of Nonlinear Transient Motion of Cables. Technical Report. David Taylor Model Basin. Washington, D.C., USA. 
Table 1: Sea states under consideration.

\begin{tabular}{lrrr}
\hline Sea state & $H$ or $H_{s}(\mathrm{~m})$ & $T$ or $T_{p}(\mathrm{~s})$ & $F_{\text {visc. }}(\mathrm{N})$ \\
\hline Regular wave 1 & 1.92 & 7.5 & 6,884 \\
Regular wave 2 & 7.578 & 12.1 & 162,790 \\
Regular wave 3 & 7.136 & 14.3 & 97,378 \\
Regular wave 4 & 7.574 & 20 & 61,467 \\
Regular wave 5 & 10.304 & 12.1 & 409,244 \\
Regular wave 6 & 10.74 & 14.3 & 331,979 \\
Regular wave 7 & 11.122 & 20 & 194,632 \\
Operational 1 & 1.916 & 7.5 & 6,841 \\
Operational 2 & 7.006 & 12.1 & 128,640 \\
Design & 10.39 & 14.3 & 300,569 \\
\hline
\end{tabular}

Table 2: Gross wind turbine properties.

\begin{tabular}{lr}
\hline Rotor diameter & $126 \mathrm{~m}$ \\
Hub height above SWL & $90 \mathrm{~m}$ \\
Overhang & $10.58 \mathrm{~m}$ \\
Shaft tilt & $0 \mathrm{deg}$ \\
Precone & $0 \mathrm{deg}$ \\
Total tower top mass & $397,160 \mathrm{~kg}$ \\
\hline
\end{tabular}


Table 3: Gross platform properties.

\begin{tabular}{lr}
\hline Draft & $20 \mathrm{~m}$ \\
Airgap & $10 \mathrm{~m}$ \\
Ballasted mass & $13,444,000 \mathrm{~kg}$ \\
Displacement & $13,987 \mathrm{~m}^{3}$ \\
Depth of CM & $14.4 \mathrm{~m}$ \\
Roll inertia about CM & $8.011 \mathrm{E} 9 \mathrm{~kg}-\mathrm{m}^{2}$ \\
Pitch inertia about CM & $8.011 \mathrm{E} 9 \mathrm{~kg}-\mathrm{m}^{2}$ \\
Yaw inertia about CM & $1.391 \mathrm{E} 10 \mathrm{~kg}-\mathrm{m}^{2}$ \\
\hline
\end{tabular}

Table 4: Platform quadratic drag coefficients.

\begin{tabular}{lr}
\hline DOF & Coefficient \\
\hline Surge & $1.25 \mathrm{E} 6 \mathrm{~N}^{2} \mathrm{~s}^{2} / \mathrm{m}^{2}$ \\
Sway & $9.50 \mathrm{E} 5 \mathrm{~N}-\mathrm{s}^{2} / \mathrm{m}^{2}$ \\
Heave & $3.88 \mathrm{E} 6 \mathrm{~N}-\mathrm{s}^{2} / \mathrm{m}^{2}$ \\
Roll & $3.35 \mathrm{E} 10 \mathrm{~N}-\mathrm{s}^{2}-\mathrm{m}$ \\
Pitch & $3.35 \mathrm{E} 10 \mathrm{~N}-\mathrm{s}^{2}-\mathrm{m}$ \\
Yaw & $1.15 \mathrm{E} 10 \mathrm{~N}^{2}{ }^{2}-\mathrm{m}$ \\
\hline
\end{tabular}


Table 5: Mooring chain properties.

\begin{tabular}{lcr}
\hline Quantity & Symbol & Value \\
\hline Nominal diameter & $D$ & $77.9 \mathrm{~mm}$ \\
Link straight length & $L$ & $286 \mathrm{~mm}$ \\
Link curve radius & $R$ & $106 \mathrm{~mm}$ \\
Links per m & & $2.38 \mathrm{~m}^{-1}$ \\
Linear density & $\rho \pi d^{2} / 4$ & $116.6 \mathrm{~kg} / \mathrm{m}$ \\
Displacement per m & $\pi d^{2} / 4$ & $0.01405 \mathrm{~m}^{2}$ \\
Equivalent diameter & $\mathrm{d}$ & $133.76 \mathrm{~mm}$ \\
\hline
\end{tabular}

Table 6: Pretension and tuning of line lengths.

\begin{tabular}{lccc}
\hline Line number & 1 & 2 & 3 \\
\hline Target fairlead tension $(\mathrm{kN})$ & 1124 & 1067 & 1065 \\
\hline Original lengths & & & \\
Unstretched length $(\mathrm{m})$ & 835.35 & 835.35 & 835.35 \\
QS fairlead tension $(\mathrm{kN})$ & 1043 & 1043 & 1043 \\
LM fairlead tension $(\mathrm{kN})$ & 1036 & 1037 & 1037 \\
\hline Tuned lengths & & & \\
Unstretched length $(\mathrm{m})$ & 833.6 & 834.8 & 834.85 \\
QS fairlead tension $(\mathrm{kN})$ & 1124 & 1067 & 1065 \\
LM fairlead tension $(\mathrm{kN})$ & 1124 & 1070 & 1068 \\
\hline
\end{tabular}


Table 7: Fairlead tension RAO comparison.

\begin{tabular}{ccrrrrrr}
\hline & \multicolumn{3}{c}{ Magnitude difference } & \multicolumn{2}{c}{ Phase difference } \\
\hline Wave & Model & fair. 1 & fair. 2 & fair. 3 & fair. 1 & fair. 2 & fair. 3 \\
\hline 1 & LM & $50 \%$ & $39 \%$ & $88 \%$ & $-15^{\circ}$ & $-11^{\circ}$ & $-10^{\circ}$ \\
1 & QS & $-67 \%$ & $-72 \%$ & $-68 \%$ & $112^{\circ}$ & $100^{\circ}$ & $117^{\circ}$ \\
\hline 2 & LM & $-3 \%$ & $-4 \%$ & $-6 \%$ & $-3^{\circ}$ & $-5^{\circ}$ & $-8^{\circ}$ \\
2 & QS & $-63 \%$ & $-57 \%$ & $-54 \%$ & $90^{\circ}$ & $69^{\circ}$ & $72^{\circ}$ \\
\hline 3 & LM & $-2 \%$ & $-10 \%$ & $-10 \%$ & $3^{\circ}$ & $-15^{\circ}$ & $-8^{\circ}$ \\
3 & QS & $-60 \%$ & $-31 \%$ & $-18 \%$ & $81^{\circ}$ & $56^{\circ}$ & $55^{\circ}$ \\
\hline 4 & LM & $-6 \%$ & $-12 \%$ & $-4 \%$ & $2^{\circ}$ & $3^{\circ}$ & $5^{\circ}$ \\
4 & QS & $-62 \%$ & $-63 \%$ & $-63 \%$ & $85^{\circ}$ & $58^{\circ}$ & $66^{\circ}$ \\
\hline 5 & LM & $1 \%$ & $0 \%$ & $1 \%$ & $-4^{\circ}$ & $-1^{\circ}$ & $-3^{\circ}$ \\
5 & QS & $-74 \%$ & $-62 \%$ & $-59 \%$ & $75^{\circ}$ & $59^{\circ}$ & $65^{\circ}$ \\
\hline 6 & LM & $-1 \%$ & $-6 \%$ & $-6 \%$ & $0^{\circ}$ & $-4^{\circ}$ & $-6^{\circ}$ \\
6 & QS & $-72 \%$ & $-43 \%$ & $-30 \%$ & $74^{\circ}$ & $58^{\circ}$ & $46^{\circ}$ \\
\hline 7 & LM & $0 \%$ & $-8 \%$ & $-1 \%$ & $-2^{\circ}$ & $3^{\circ}$ & $6^{\circ}$ \\
7 & QS & $-68 \%$ & $-67 \%$ & $-69 \%$ & $76^{\circ}$ & $53^{\circ}$ & $60^{\circ}$ \\
\hline
\end{tabular}

Table 8: Uncoupled fatigue and extreme mooring loads for design sea state and dynamic wind.

\begin{tabular}{rrrrrrr}
\hline & \multicolumn{2}{c}{ Damage-equivalent load $(\mathrm{kN})$} & \multicolumn{3}{c}{ Extreme load $(\mathrm{kN})$} \\
\hline & fairlead 1 & fairlead 2 & fairlead 3 & fairlead 1 & fairlead 2 & fairlead 3 \\
\hline Test & 1040 & 88.3 & 78.5 & 5120 & 1170 & 1090 \\
LM & 966 & 94.2 & 81.3 & 5680 & 1200 & 1130 \\
QS & 273 & 30.8 & 26.5 & 3800 & 1010 & 979 \\
\hline
\end{tabular}


Table 9: Coupled fatigue and extreme mooring loads for design sea state and dynamic wind.

\begin{tabular}{lrrrrrr}
\hline & \multicolumn{2}{c}{ Damage-equivalent load $(\mathrm{kN})$} & \multicolumn{3}{c}{ Extreme load $(\mathrm{kN})$} \\
\hline & fairlead 1 & fairlead 2 & fairlead 3 & fairlead 1 & fairlead 2 & fairlead 3 \\
\hline Test & 1040 & 88.3 & 78.5 & 5120 & 1170 & 1090 \\
LM & 522 & 56.7 & 57.2 & 3190 & 994 & 995 \\
QS & 293 & 35.0 & 35.2 & 2910 & 970 & 972 \\
\hline
\end{tabular}




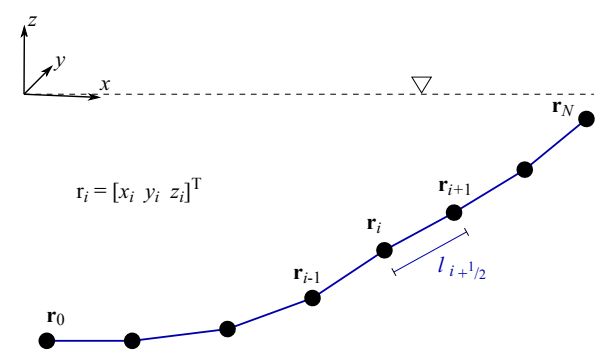

Figure 1: Mooring line discretization and indexing.

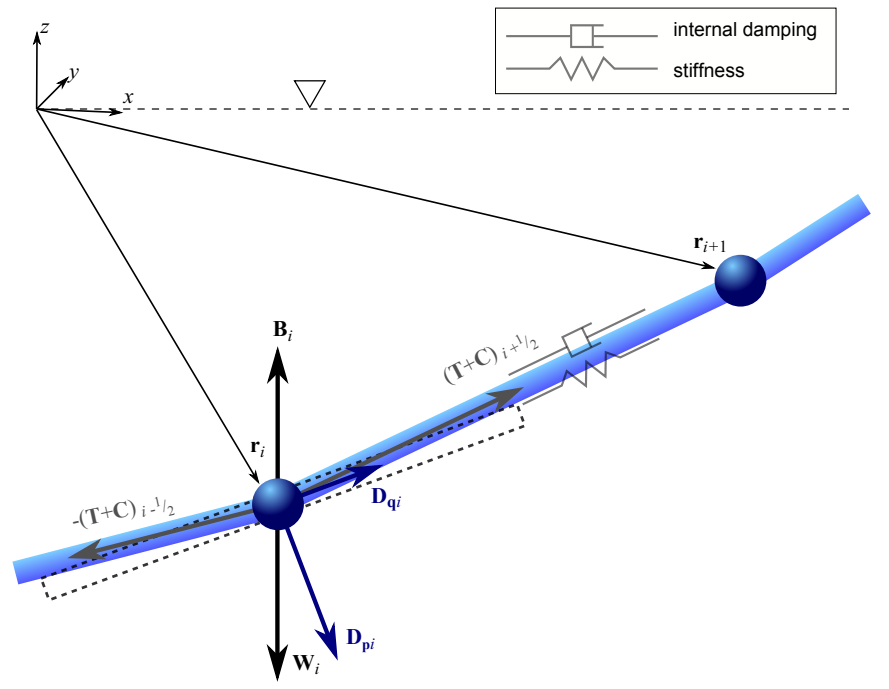

Figure 2: Internal and external cable forces. 


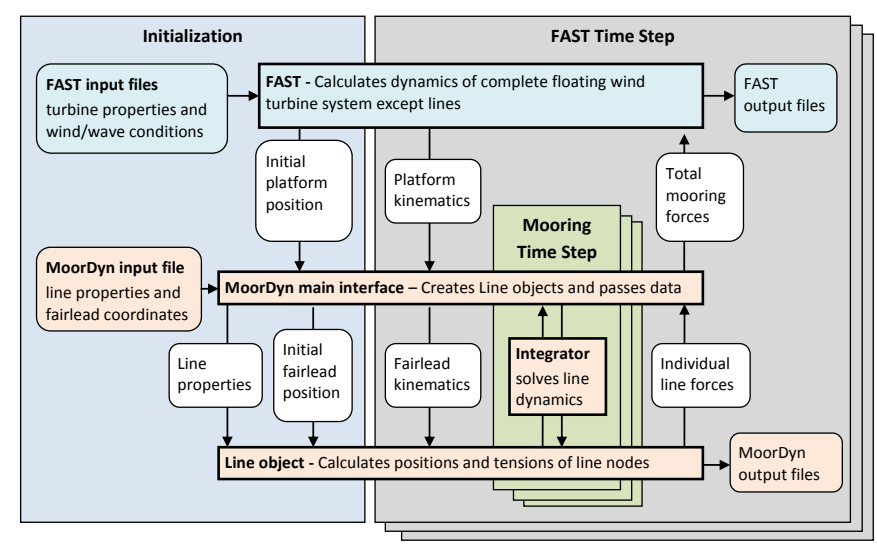

Figure 3: Overview of lumped-mass mooring model coupling with FAST v.7.

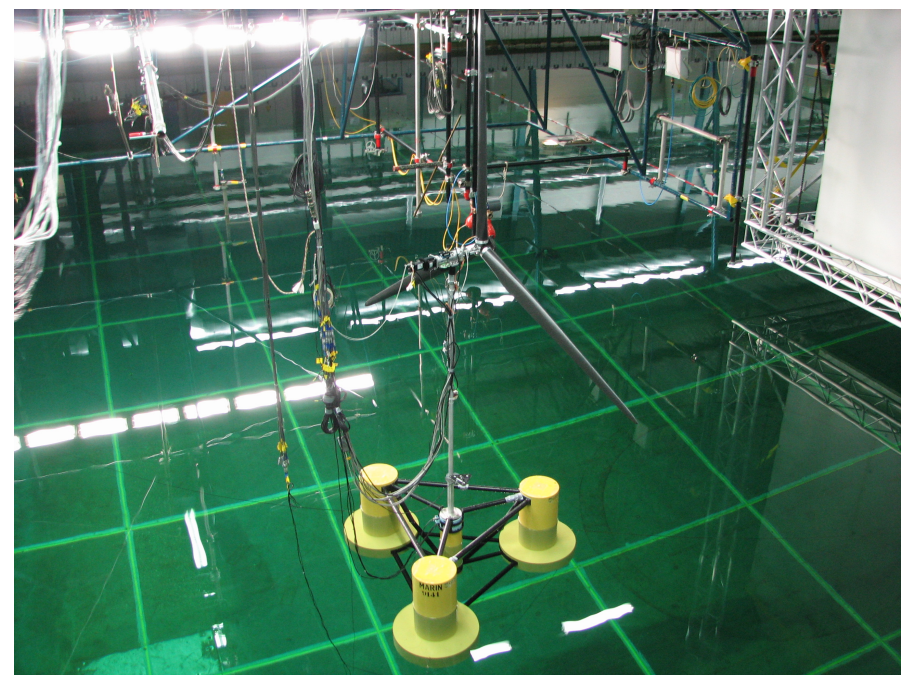

Figure 4: 1:50-scale DeepCwind semisubmersible tested at MARIN in 2011. 


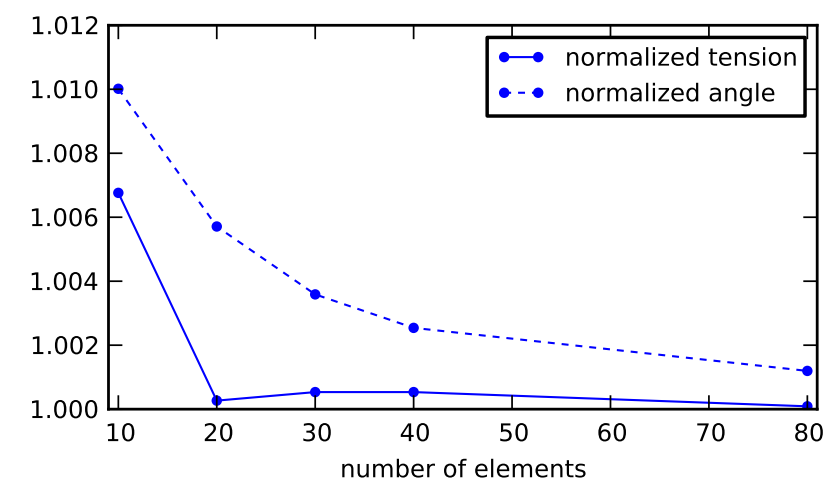

Figure 5: Equilibrium fairlead tensions and angles normalized by quasi-static result.

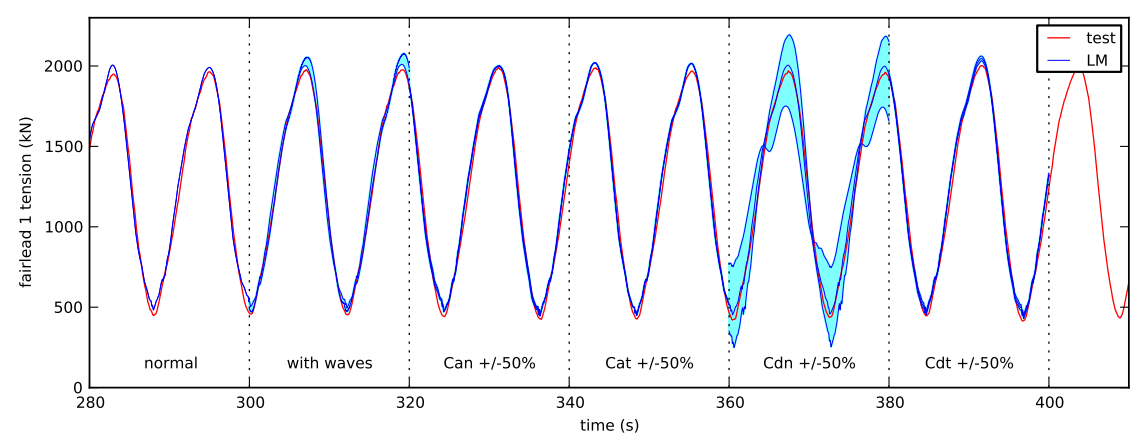

Figure 6: Fairlead 1 tensions for regular wave 5 with $\pm 50 \%$ variation of hydrodynamic coefficients. 


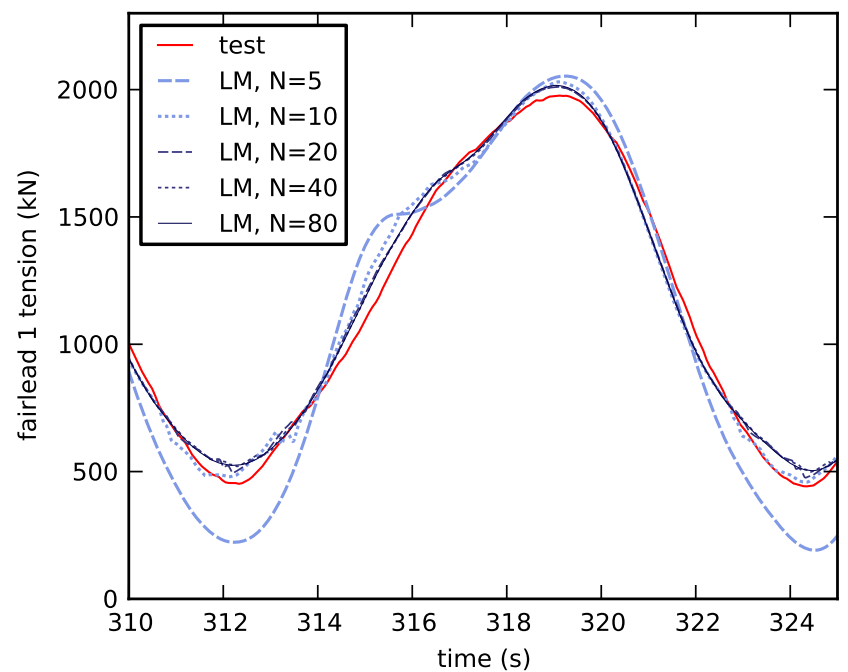

Figure 7: Fairlead 1 tensions for regular wave 5 with different numbers of cable segments. 

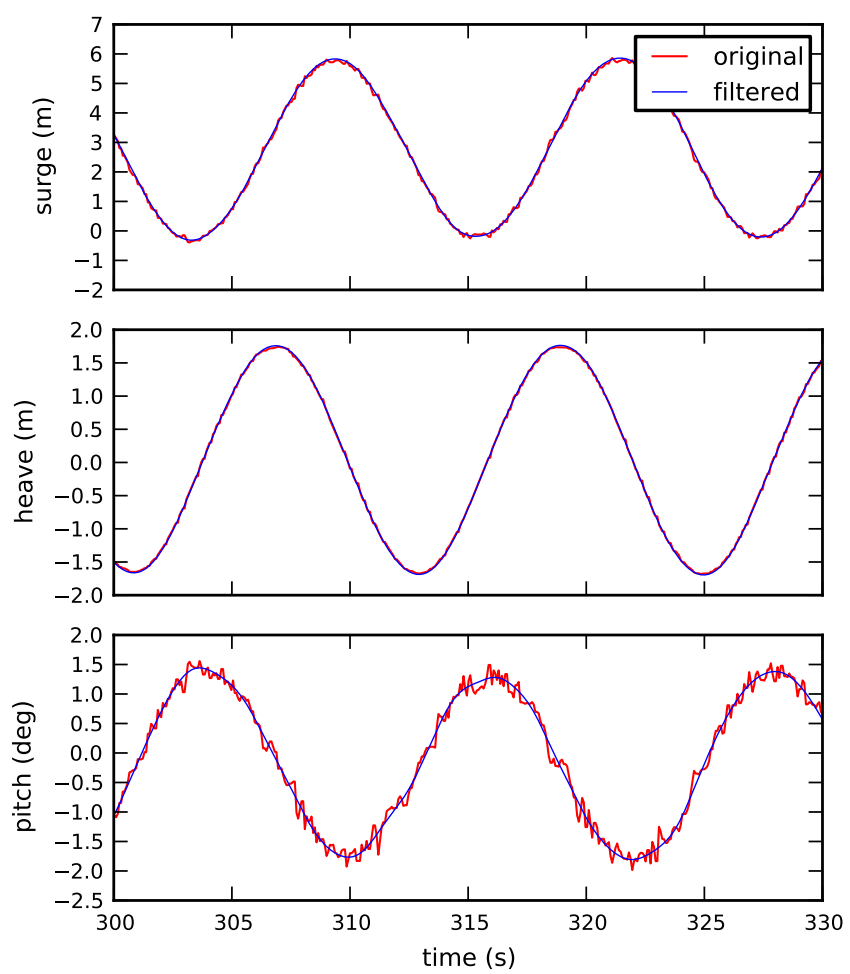

Figure 8: Sample of original and filtered platform motions from regular wave 5. 

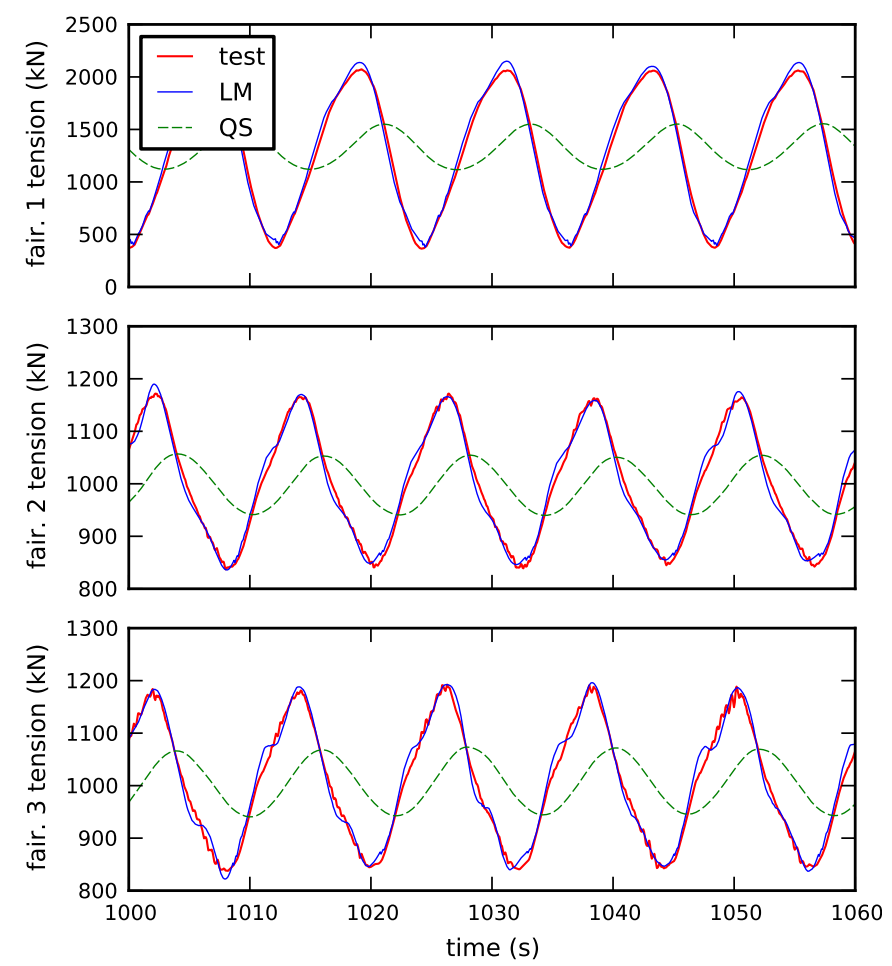

Figure 9: Fairlead tensions in regular wave 5. 

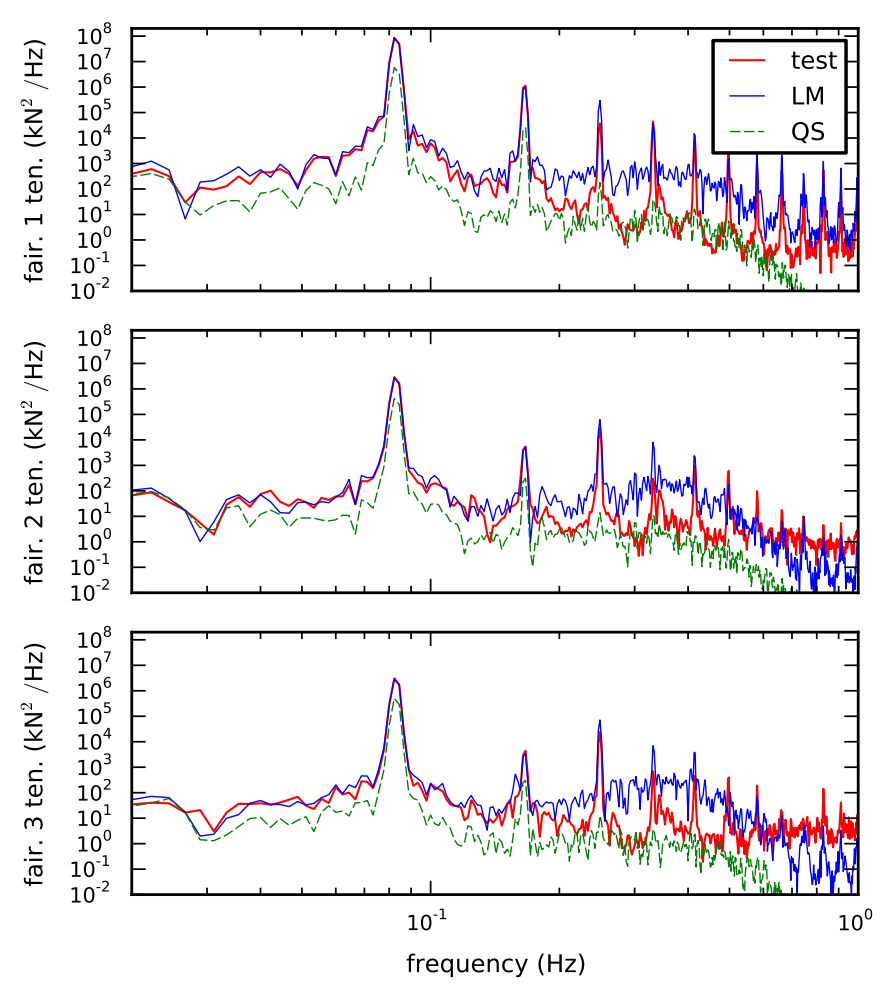

Figure 10: Fairlead tension PSDs in regular wave 5. 


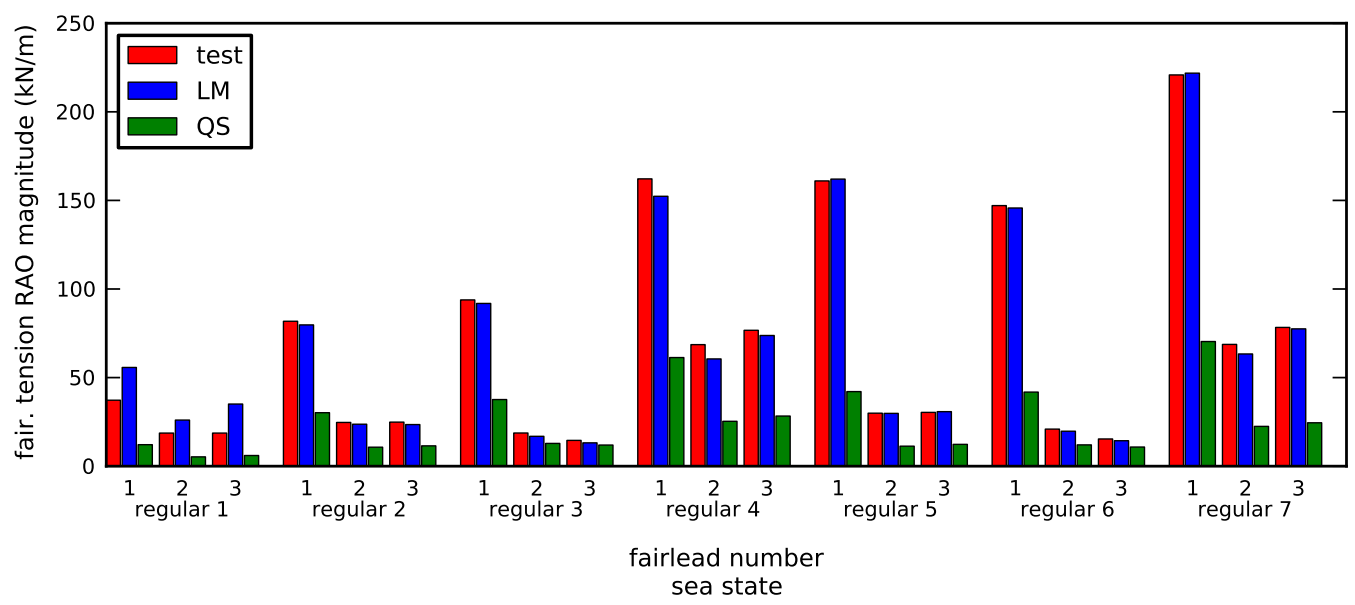

Figure 11: Comparison of fairlead tension RAO magnitudes from test data, LM model, and QS model.

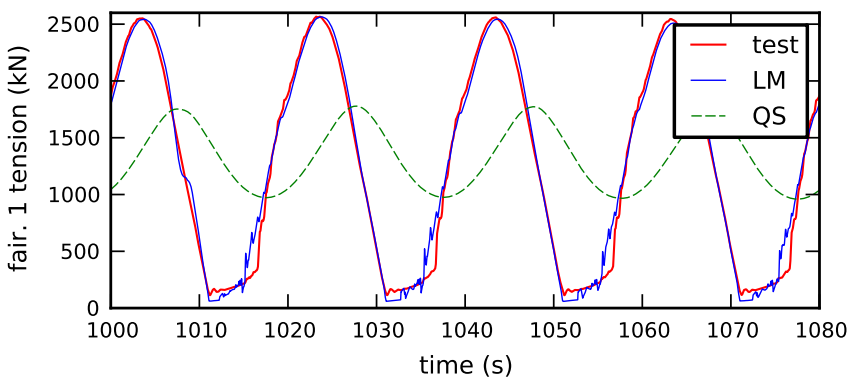

Figure 12: Slack line conditions apparent in fairlead 1 tension for regular wave 7. 

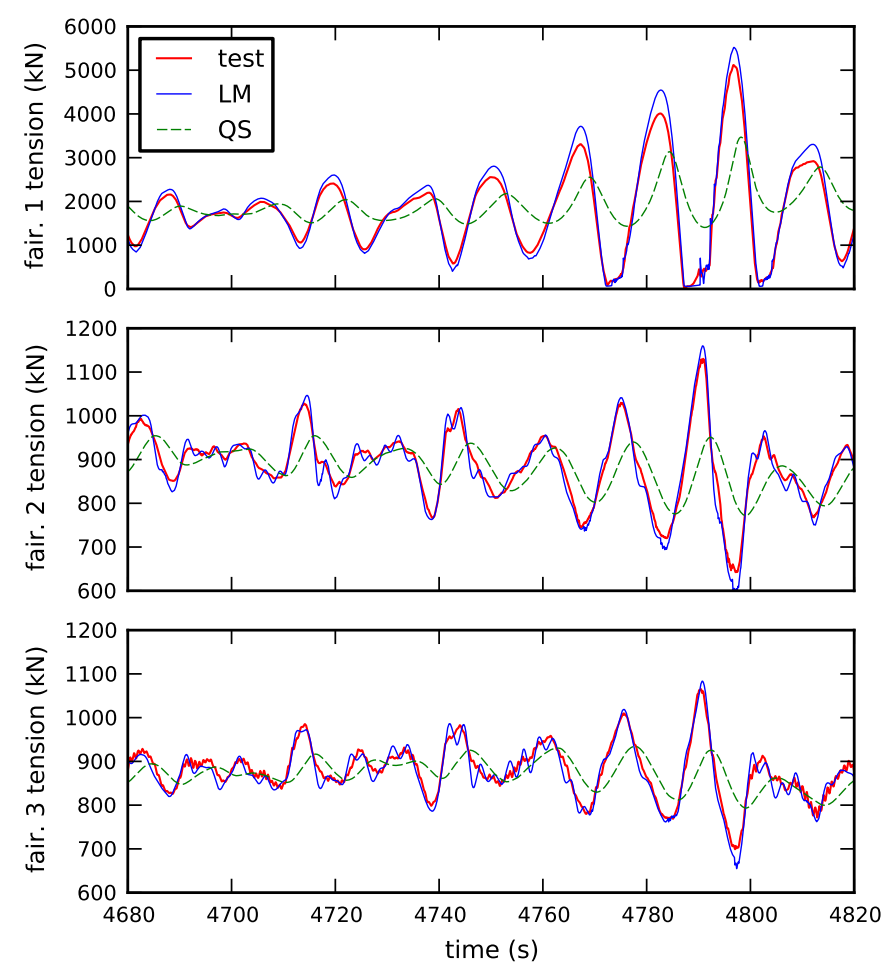

Figure 13: Fairlead tensions for design wave and dynamic wind. 

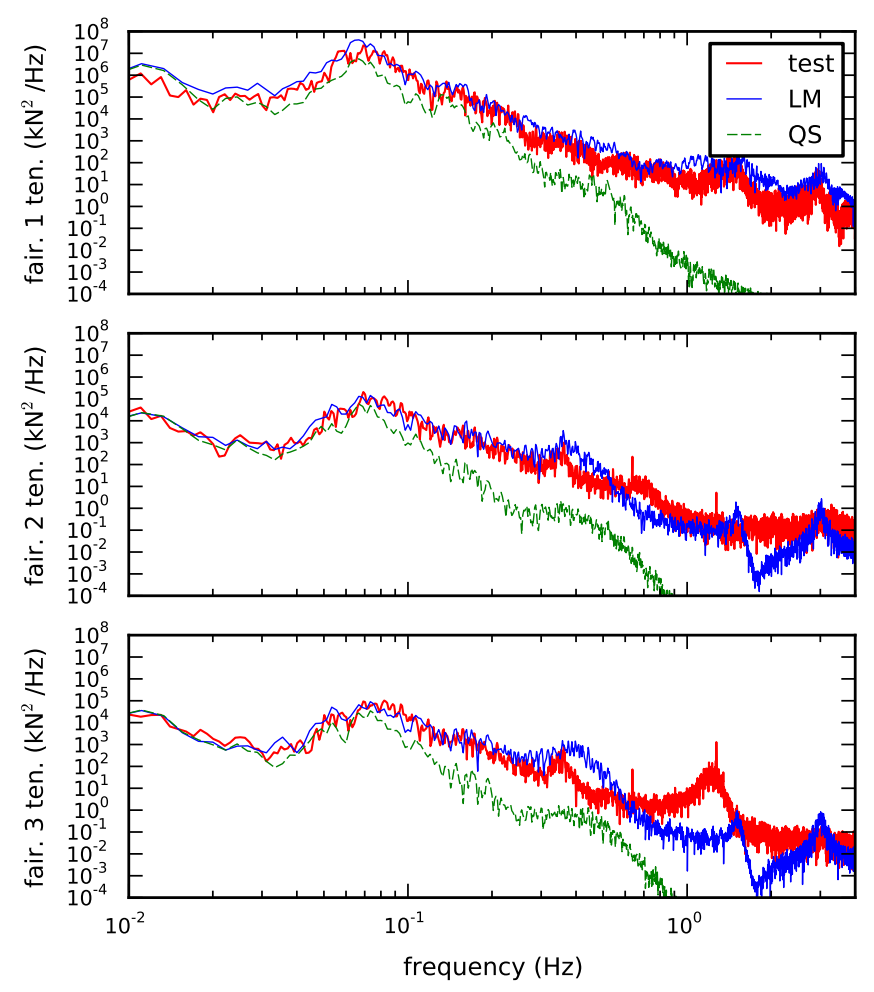

Figure 14: Fairlead tension PSDs for design wave and dynamic wind. 

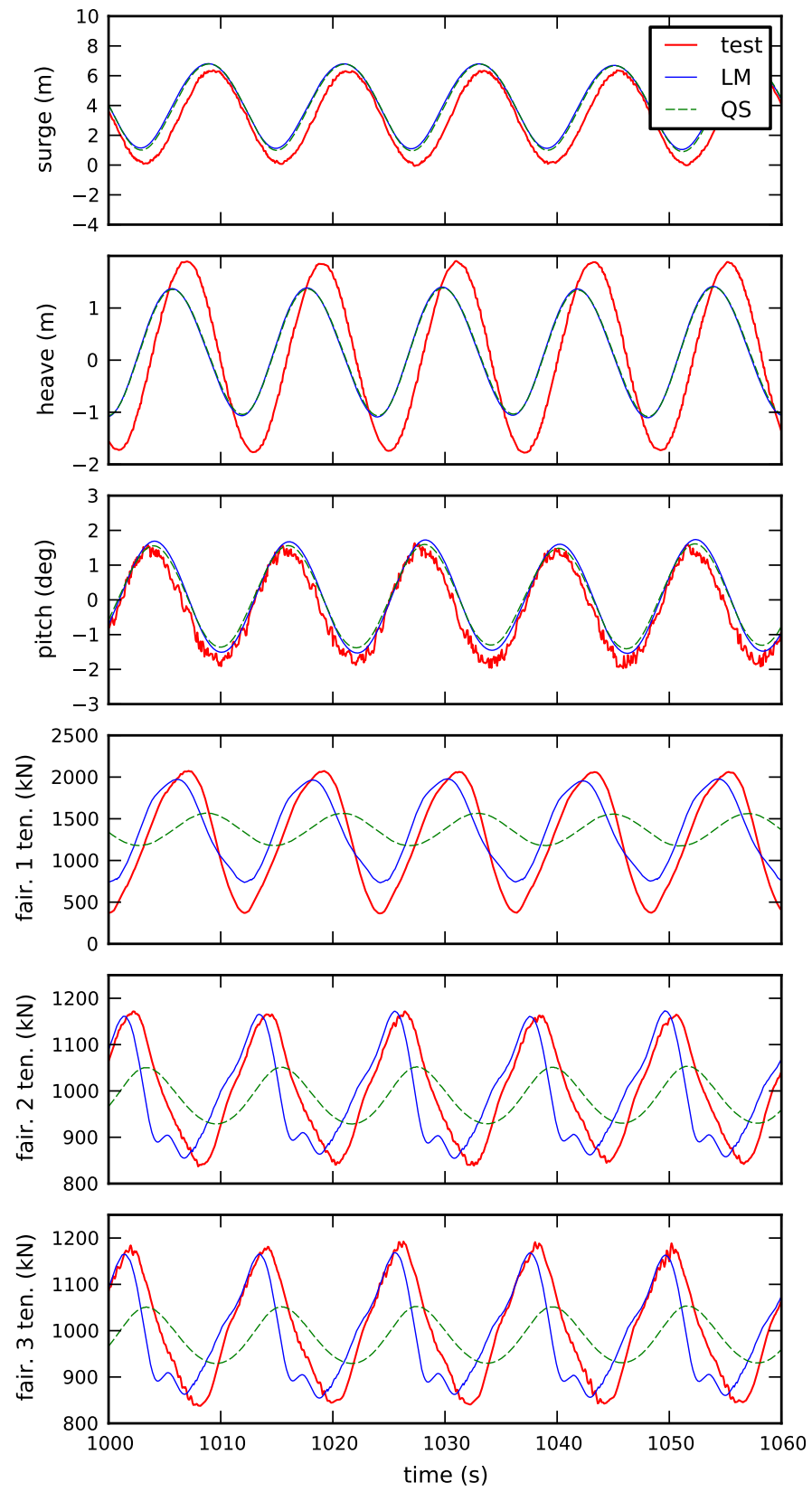

Figure 15: Platform motions and fairlead tensions for regular wave 5. 


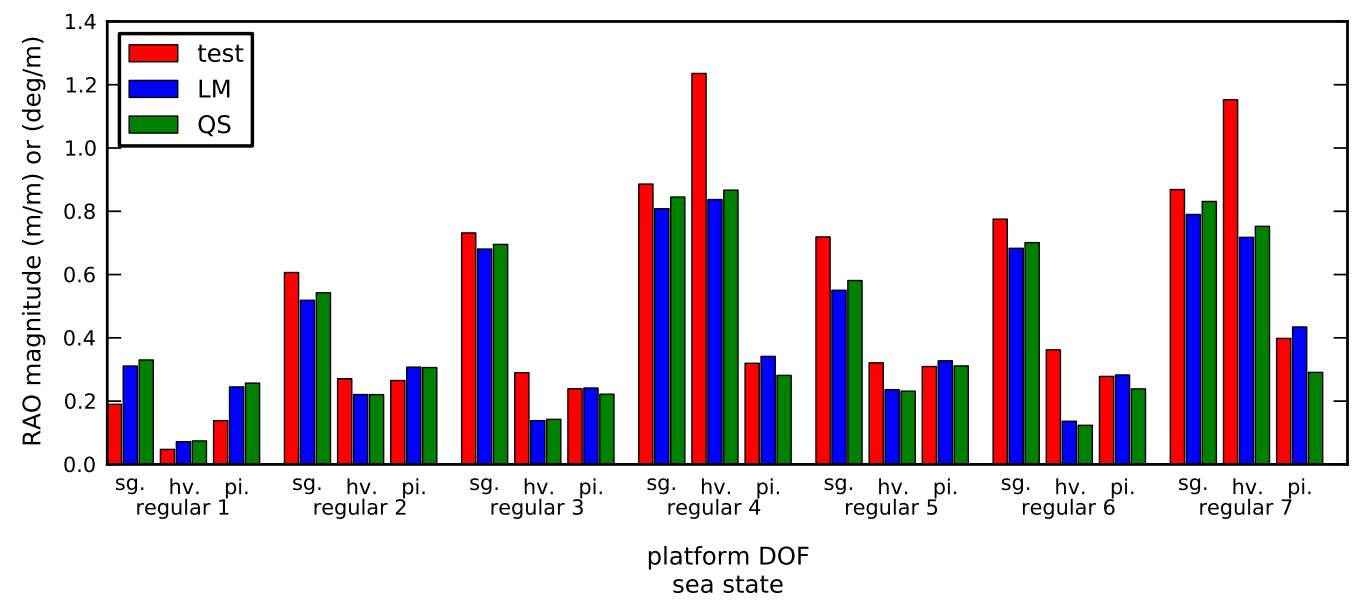

Figure 16: Comparison of platform motion RAO magnitudes from test data, LM model, and QS model.

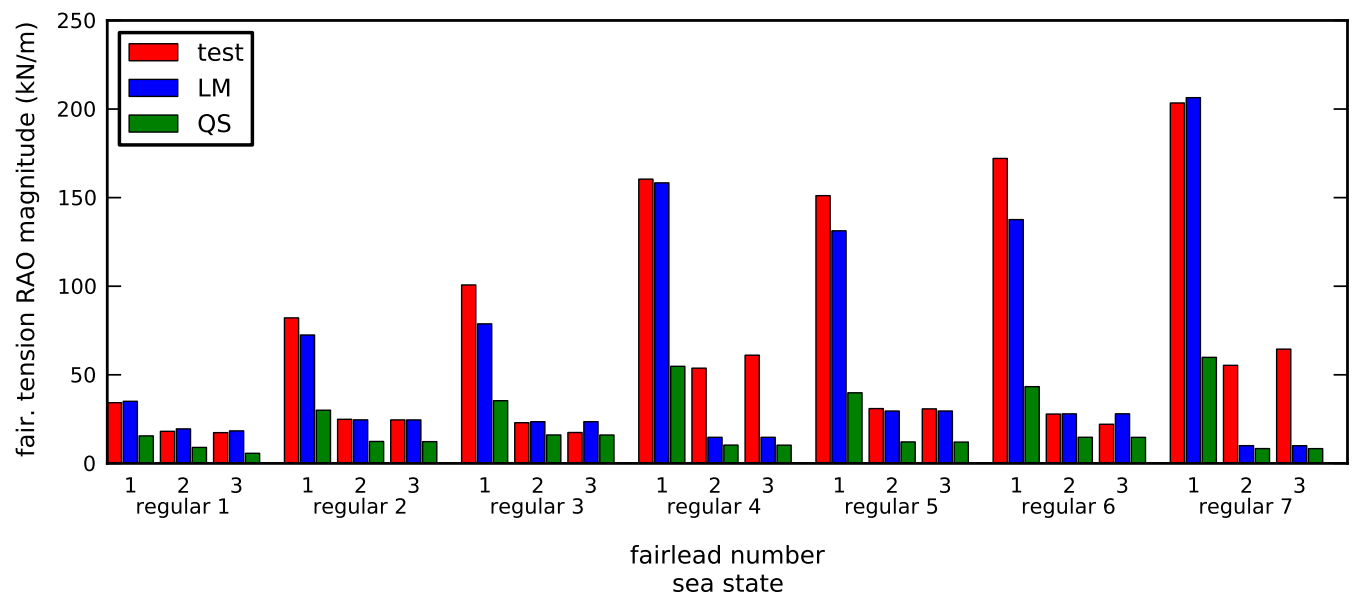

Figure 17: Comparison of fairlead tension RAO magnitudes from test data, LM model, and QS model. 


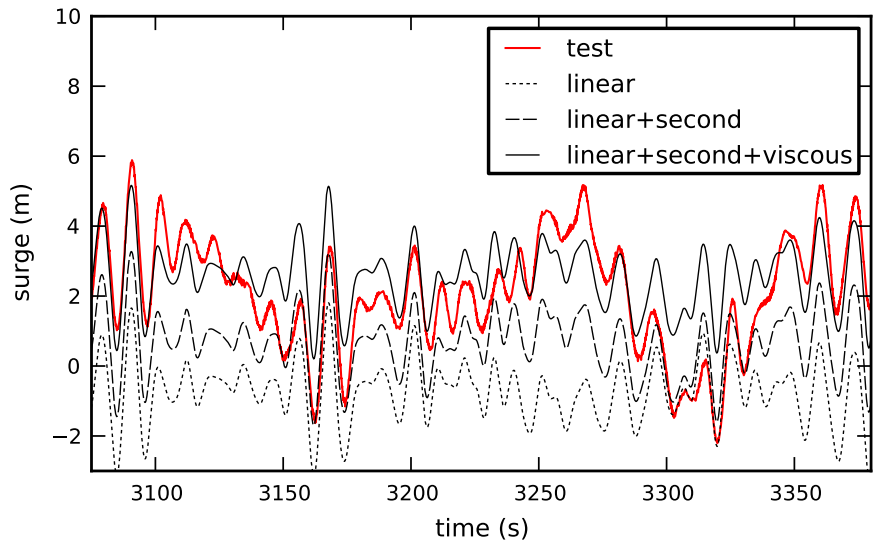

Figure 18: Surge motion in operational 2 sea state with different drift contributions 

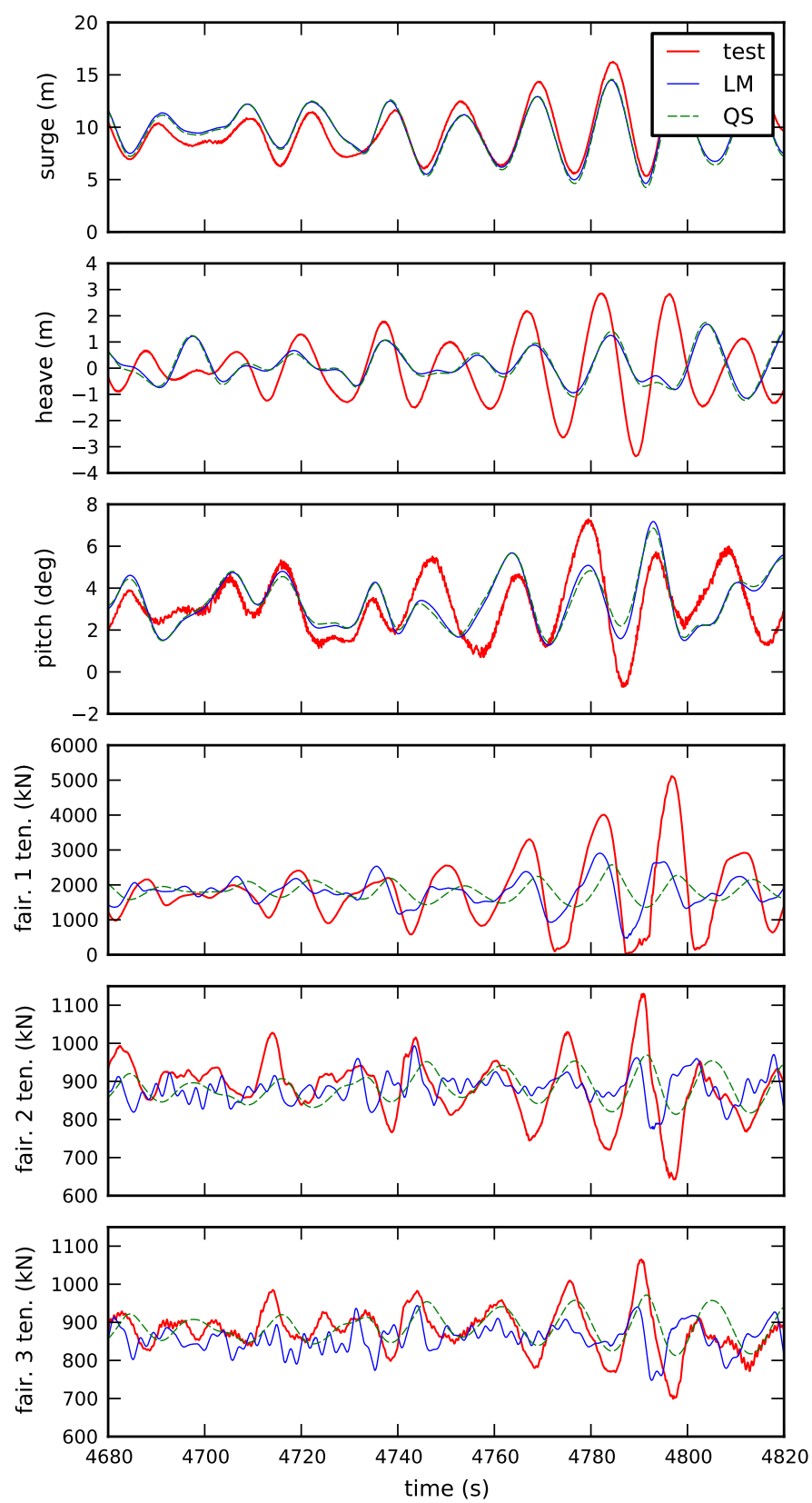

Figure 19: Platform motion and fairlead tension time series for design sea state with dynamic wind. 